\title{
Diabetes melito: plantas e princípios ativos naturais hipoglicemiantes
}

\author{
Giuseppina Negri
}

Universidade Federal de São Paulo, UNIFESP, São Paulo - SP

*Correspondência:

G. Negri

Universidade Federal de São Paulo -

UNIFESP

E-mail: gnegri@terra.com.br
O diabetes melito é considerada como uma sindrome que é, quanto a etiologia e patogênese, caracterizada por alterar a homeostase do organismo, por distúrbios metabólicos complexos e primários dos carboidratos, que envolvem secundariamente, porém de forma importante, lipídeos e proteínas. Grande número de espécies de plantas tem sido usado experimentalmente para tratar os sintomas do diabetes melito e a distância filogenética entre este grupo de plantas é forte indicação da natureza variada de seus constituintes. Tem sido constatado que muitas substâncias extraídas de plantas reduzem o nivel de glicose no sangue. A grande diversidade de classes químicas indica que uma variedade de mecanismos de ação deve estar envolvida na redução do nível de glicose no sangue. Algumas destas substâncias podem ter potencial terapêtico enquanto outras podem produzir hipoglicemia como um efeito colateral devido à sua toxicidade, especialmente hepatotoxidade. Este artigo apresenta uma revisão atualizada e acrescenta mais plantas e princípios ativos hipoglicemiantes à extensa lista existente nos artigos de revisão anteriores.

\author{
Unitermos \\ - Diabetes melito \\ - Plantas hipoglicemiantes \\ - Princípios ativos \\ hipoglicemiantes
}

\section{INTRODUÇÃO}

\section{Diabetes melito - Considerações gerais}

O diabetes melito situa-se entre as dez principais causas de morte nos países ocidentais e, apesar dos progressos em seu controle clínico, ainda não foi possível controlar de fato suas conseqüências letais. Esta doença é um distúrbio crônico, que afeta o metabolismo de carboidratos, de gorduras e proteínas. Aspecto característico do diabete melito é a hiperglicemia, que se constitui em reflexo da deterioração na utilização dos carboidratos (glicose) em virtude de resposta defeituosa ou deficiente à secreção de insulina (Bransome, 1992). O diabetes melito compreende série de sintomas comuns tais como sede e fome excessivas, fraqueza muscular, perda de peso e elevação do nível de glicose no sangue, o que resulta na excreção da glicose pela urina (Robbins et al., 1991; Shoelson, 1995; Berne et al., 2000; Godoy, 2000; Said et al., 2002). Os recursos financeiros envolvidos no tratamento, recuperação e manutenção de pacientes portadores da patologia são altos para a sociedade.

O diabetes melito é uma condição na qual o organismo perdeu, parcialmente, o poder de "queimar" os açúcares fornecidos pelos alimentos ingeridos. Como resultado, o açúcar que não é queimado acumula-se no sangue e não se transforma em energia (Bennett, 1983; Lienhard et al., 1992). O excesso de açúcar não queimado no sangue, com 
a conseqüente falta de produção de energia, dará origem aos sintomas de fraqueza, perda de peso, entre outros. Na realidade, sabe-se que o diabetes melito é bem mais complexo, pois a insulina é um modulador primário do equilíbrio metabólico de carboidratos, proteínas e gorduras (Nogueira, 2003; Silva et al., 2003).

O pâncreas endócrino está situado abaixo e atrás do estômago, sendo uma glândula que pesa cerca de $250 \mathrm{~g}$ e é representado por aglomerados de células microscópicas denominadas ilhotas de Langerhans e numerosas outras células distribuídas na porção exócrina e no epitélio de revestimento dos canais excretores. No pâncreas são produzidos três hormônios importantes: insulina, glucágon e somatostatina (Clayton et al., 1993; Godoy, 2000).

\section{PLANTAS HIPOGLICEMIANTES}

Muitas espécies de plantas têm sido usadas etnofarmacologicamente ou experimentalmente para tratar dos sintomas do diabetes melito (Oliveira, 1989; Ivorra et al., 1989; Rahman, Zaman, 1989; Handa, Chawla, 1989; Neef et al., 1995; Johns, Chapman, 1995; Marles, Farnsworth, 1995; Ernst, 1997; Pereira, 1997; Kar et al., 1999, 2003; Lamba et al., 2000; Novaes et al., 2001; Mccune, Jonhns, 2002; Said et al., 2002; Volpato et al., 2002; Grover et al., 2002b; Syem et al., 2002; Huo et al., 2003; Elder, 2004; Saxena, Vikram, 2004). Estas plantas representam mais de 725 gêneros em 183 famílias, estendendo-se fisiologicamente das algas marinhas e fungos para plantas, tais como as compostas. A distância filogenética entre este grupo de famílias é forte indicação da natureza variada de seus constituintes ativos (Tabela I) (Ivorra et al., 1989; Marles, Farnsworth, 1995; Johns, Chapman, 1995; Pereira, 1997; Pérez Gutiérrez, 1998, 2002a; Lamba et al., 2000). Na medicina chinesa tradicional, 82 plantas medicinais têm sido usadas como medicamentos naturais para o tratamento do diabetes melito e suas complicações (Li et al., 2004). A maioria das plantas que são utilizadas como antidiabéticas ao serem avaliadas farmacologicamente demonstraram ter atividade hipoglicemiante e possuir constituintes químicos que podem ser utilizados como modelos para novos agentes hipoglicemiantes. Entretanto, as análises posteriores revelaram grande variedade de mecanismos de ação que podem levar ao efeito hipoglicemiante, nem todos terapeuticamente úteis (Marles, Farnsworth,1995; Huo et al., 2003; Said et al., 2002). Na região sudoeste do Marrocos, 37 plantas são usadas no tratamento do diabetes, porém devem ser utilizadas com muito cuidado, especialmente no diabetes tipo I, porque algumas dessas plantas medicinais podem provocar acidentes hipoglicêmicos (Eddouks et al., 2002).
Os modelos mais utilizados in vivo para o estudo do diabetes são roedores tratados com aloxano ou estreptozotocinas (STZ) (Marles, Farnsworth, 1995), também conhecida como estreptozocina (STZ) é um glicosídeo nitrosourea natural isolado do Streptomyces achromogenes. A STZ estimula a produção de radicais livres, o que leva à destruição e disjunção das células $\beta$ das ilhotas de Langerhans do pâncreas. Este xenobiótico tem sido usado para induzir o diabetes com concomitante deficiência de insulina. Uma dose simples em ratos pode produzir um modelo experimental do diabetes tipo II (Marles, Farnsworth, 1995). O aloxano, um derivado da pirimidina, é uma toxina muito seletiva das células $\beta$-pancreáticas por causar a inibição da glicoquinase. No entanto, apesar de ser um bom modelo para o diabetes melito, há muitos problemas devido à sua instabilidade química, metabolismo rápido e alguns fatores, tais como dieta e idade, que tornam quase impossível estabelecer uma relação clara entre as doses de aloxano e sua concentração efetiva no pâncreas (Marles, Farnsworth, 1995).

O mecanismo de ação pelos quais as plantas baixam a taxa de glicose do sangue pode ser atribuído aos seguintes fatores: aumento da liberação de insulina através da estimulação das células $\beta$-pancreáticas; resistência aos hormônios que aumentam a taxa de glicose; aumento do número e da sensibilidade do sítio receptor de insulina; diminuição da perda de glicogênio; aumento do consumo de glicose nos tecidos e orgãos; eliminação de radicais livres; resistência à peroxidação de lipídeos; correção da desordem metabólica causada em lipídeos e proteínas e estímulo ao aumento da microcirculação do sangue no organismo (Marles, Farnsworth,1995; Huo et al., 2003; Said et al., 2002, Li et al., 2004; Volpato et al., 2002).

Algumas plantas associadas ao tratamento do diabetes são consideradas tóxicas. Há muitos efeitos tóxicos das plantas, os quais podem resultar em hipoglicemia, tais como, hepatotoxicidade e bloqueio $\beta$-adrenérgico. Detalhes tais como, identificação da planta, parte a ser usada, preparação,

TABELA I - Famílias das plantas que possuem atividade hipoglicemiante

\begin{tabular}{lcc}
\hline Família & Espécies citadas & Total de espécies \\
\hline Fabaceae & 127 & 18.000 \\
Asteraceae & 98 & 21.300 \\
Lamiaceae & 36 & 3.500 \\
Liliaceae & 35 & 6.460 \\
Poaceae & 30 & 10.000 \\
Euphorbiaceae & 30 & 7.000 \\
\hline
\end{tabular}

Fonte: Marles e Farnsworth, 1995 
padronização química e biológica do extrato, estabilidade do extrato, dosagens terapêuticas, efeitos colaterais, interações medicamentosas e alimentares e contra-indicações devem ser incorporados à farmacopéia nacional. A toxicidade é influenciada pela parte da planta usada na preparação do extrato, método de preparação e rota de administração. A alergenicidade e fotossensibilização são outros aspectos de toxicidade, os quais não são revelados nos testes de toxicidade aguda e que ainda representam riscos significativos (Marles, Farnsworth,1995; Huo et al., 2003; Said et al., 2002; Li et al., 2004).

Extratos dos frutos, folhas e raízes de Momordica charantia Linn (Cucurbitaceae) são eficientes no tratamento da diabetes tipo II (Miura et al., 2004; Senanayake et al., 2004). Os extratos de Momordica charantia e Eugenia Jambolana Linn (Myrtaceae) protegeram os glomérulos dos efeitos prejudiciais do diabetes e impediram o aumento do volume da urina, a excreção de albumina na urina e a hipertrofia renal, como também causaram redução na taxa de glicose no plasma. O extrato de Mormodica charantia continuou a exercer um efeito hipoglicêmico, mesmo quando a maior parte das células $\beta$ foram destruídas, indicando um efeito insulinomimético direto (Grover et al., 2001). A hiperglicemia e hiperinsulinemia foram atenuadas pela administração oral dos extratos aquosos de Mormodica charantia e Eugenia Jambolana (Vikrant et al., 2001). Tratamento realizado com o extrato aquoso liofilizado de Mormodica charantia, um vegetal comestível, parece ser uma alternativa segura para reduzir os níveis de glicose no sangue (Virdi et al., 2003). A decocção feita com as folhas de Eugenia jambolana não apresentou nenhum efeito hipoglicêmico nos ratos que tiveram o diabetes induzido por STZ (Pepato et al., 2001; Teixeira et al., 2000).

Extratos aquosos dos frutos de Mormodica cymbalaria Hook F. (Cucurbitaceae) produziram diminuição máxima na concentração de glicose em ratos diabéticos depois de 3 horas da administração, porém não foi observada atividade hipoglicemiante nos ratos normais (Kameswara Rao et al., 2001b). O tratamento oral com o extrato aquoso do fruto de Momordica cymbalaria durante 6 semanas mostrou atividades anti-hiperglicemiante e anti-hiperlipidemica significativas em ratos que tiveram o diabetes induzido por aloxano (Kameswara Rao et al., 2003, 2001b).

Extratos de Mormodica charantia e Mucuna pruriens (L.) DC. (Fabaceae) exerceram efeito hipoglicemiante provavelmente através do aumento da atividade da fosfofrutoquinase, a principal enzima envolvida na etapa glicolítica (Rathi et al., 2002a). O diabetes é reconhecido como fator de risco para a catarata, a qual permanece como a maior causa de cegueira no mundo. Os extratos de
Mormodica charantia e Eugenia jambolana impediram o desenvolvimento da catarata, enquanto que o efeito protetor foi menos efetivo com Tinospora cordifolia (Willd) Miers ex Hook F. and Thoms (Menispermaceae) e Mucuna pruriens, além de produzirem redução significativa do nível de glicose no plasma (Rathi et al., 2002b).

A Tinospora cordifolia tem sido usada como um tônico, possuindo atividades revitalizadoras, antidiabéticas, imunomoduladoras, anti-hepatotóxicas e antipiréticas (Grover et al., 2001, 2002b). O extrato das raízes da Tinospora cordifolia possui atividade antioxidante, a qual exerce ação benefica contra as alterações patológicas causadas pela presença de superóxido e radicais hidroxila no diabetes induzido por aloxano (Prince et al., 2001).

Extrato aquoso das sementes de Syzygium cumini Linn (sinonímia Eugenia jambolana) (Myrtaceae) reduziu os danos causados nos tecidos do cérebro de ratos diabéticos, causou decréscimo significativo nos lipídeos e nas substâncias que reagem com o ácido tiobarbitúrico, aumentou a concentração das enzimas catalase e superóxido dismutase no cérebro de ratos que tiveram o diabetes induzido por aloxano. Os extratos aquosos e etanólicos exerceram efeito hipoglicemiante mais acentuado do que a glibenclamida (Prince et al., 2003). O extrato aquoso de Syzygium alternifolium (Wt) Walp (Myrtaceae) apresentou excelente efeito hipoglicemiante tanto nos ratos normais, quanto nos ratos que tiveram o diabetes induzido por aloxano. As frações hexânicas e etanólicas também mostraram atividade hipoglicemiante, porém o efeito é menor que no extrato aquoso (Rao, Rao, 2001).

O mais provável mecanismo de ação para explicar a atividade hipoglicemiante da Murraya koeingii L. Spreng (Rutaceae) é a liberação de insulina, uma vez que o extrato desta planta não é muito efetivo no tratamento de casos graves de diabetes com níveis altos de glicose (Yadav et al., 2002).

Dieta utilizando Brassica juncea L. (Brassicaceae) como tempero mostrou efeito anti-hipoglicemiante significativo em ratos que tiveram o diabetes induzido por aloxano, mas não apresentou efeito sobre os ratos que tiveram diabetes induzida por estreptozotocina, falhando também em modular o glicogênio hepático e a atividade das enzimas que são as enzimas-chave no metabolismo de carboidratos (glicoquinase, hexoquinase e fosfofrutoquinase) (Grover et al., 2002a). Extrato de Brassica juncea impediu significativamente o aumento nos níveis de creatina, retardando o desenvolvimento da nefropatia diabética (Grover et al., 2003).

O extrato aquoso das folhas de Zygophyllum gaetulum Emb. And Maire (Zygophylaceae) é um dos 
remédios mais tradicionais usados no Marrocos para tratamento do diabetes melito e um estudo mostrou que este extrato reduziu o nível de glicose no plasma (Jaowhari et al., 1999).

Plantas comestíveis, tais como Allium cepa L. (Liliaceae) (cebola) e Allium sativum L. (Liliaceae) (alho) usadas no tratamento do diabetes são caracterizadas por possuir concentração baixa de carboidrato e gordura, além de impedir as complicações cardiovasculares diabéticas (Baluchnejadmojarad et al., 2003). A Ipomoea aquatica Forsk, Nali (Convolvulaceae) é consumida como comestível no Srilanka e supõe-se que ela possui atividade hipoglicêmica igual à insulina (Malalavidhane et al., 2000). $\mathrm{O}$ extrato aquoso de Ipomoea aquatica foi tão efetivo quanto a tolbutamida na redução do nível de glicose no sangue dos ratos diabéticos (Malalavidhane et al., 2001).

Resultados obtidos com o extrato aquoso de Ocimum canum $\operatorname{Sim}$ (Labiatae) mostraram aumento significativo na liberação de insulina das células das ilhotas $\beta$-pancreáticas. $\mathrm{O}$ extrato de $O$. canum aumentou significativamente a liberação de insulina nas ilhotas das células $\beta$-pancreáticas in vitro isoladas e a liberação da insulina dependeu da concentração de glicose e aumentou com o aumento da concentração de $O$. canum no meio de incubação (Nyarko et al., 2002). A administração intragástrica de um extrato etanólico 50\% das folhas secas de Ocimum sanctum Linn (Labiatae) em ratos albinos que tiveram a hiperglicemia induzida experimentalmente reduziu em $30 \%$ os níveis de glicose no sangue. Em ratos que tiveram o diabetes induzido por estreptozocina a administração intragástrica do extrato também resultou na redução do nível de glicose (World Health Organization, 2002a).

Aloe vera (L.) Burm. Fil. (Liliaceae) tem sido muito usada em todo o mundo, devido às suas propriedades medicinais. O extrato aquoso da folha de Aloe vera mostrou atividade hipoglicêmica em ratos com diabetes tipo I e II, apresentando maior atividade no diabetes tipo II do que a glibenclamida. Aloe vera melhorou a cicatrização de ferimentos nos ratos que tiveram o diabetes induzido por STZ. O gel obtido da folha apresentou atividade hiperglicemiante, portanto, o extrato da folha sem o gel pode ser útil no tratamento do diabetes melito (Okyar et al., 2001).

Extrato das folhas de Biophytum sensitivum DC. syn Oxalis sensitiva L. (Oxalidaceae) mostrou efeito insulinotrópico, o qual é obtido através do estímulo da liberação ou síntese de insulina. Portanto, a atividade hipoglicemiante deste extrato pode ser atribuída ao aumento da síntese ou liberação de insulina das células $\beta$. Nos ratos nos quais o diabetes foi induzido por aloxano, os efeitos são menos expressivos, provavelmente, porque nestes animais, as células $\beta$ foram danificadas e não é possível ha- ver aumento na secreção de insulina (Puri, 2001). Acreditase que o extrato das folhas de Azadirachta indica A. Juss (Meliacaeae) bloqueie significativamente o efeito inibitório da serotonina sobre a liberação de insulina mediada pela glicose e que o efeito hipoglicemiante do extrato pode ser devido à liberação da insulina (Chattopadhay, 1999). A planta Phyllanthus sellowianus Muell. Arg. (Euphorbiaceae) é muito usada como hipoglicemiante na América do Sul (Huatyszyn et al., 1999).

Extrato de Bauhinia divaricata Linn (Leguminosae) é usado para tratar variedade de enfermidades, tais como problemas gastrintestinais e respiratórios, sendo também usado freqüentemente no tratamento do diabetes. A atividade hipoglicemiante desta planta é atribuída à sua capacidade de inibir a $\alpha$-amilase (Ankli et al., 2002). A fração $n$-butanólica do extrato das folhas de Bauhinia forticata Link (Leguminosae) foi efetiva no decréscimo do nível de glicose, provavelmente agindo através da redução da sua absorção intestinal (Silva et al., 2002). Houve melhora no metabolismo dos carboidratos, quando os ratos diabéticos foram tratados com decocção de Bauhinia forticata. No entanto, esta melhora não parece estar relacionada à inibição da glicogênese, nem mesmo o extrato parece agir de maneira similar à insulina ou sulfoniluréias, embora possa agir através da inibição da neoglicogênese de maneira similar à biguanida (Pepato et al., 2002). Os extratos de Bauhinia forticata podem reduzir a taxa de glicose, triglicerídeos e colesterol, sendo útil no tratamento do diabetes tipo II (Lino et al., 2004). O extrato aquoso das folhas de Bauhinia megalandra G. (Leguminosae) inibiu a absorção da glicose pelo intestino, efeito este dependente da concentração do extrato (Gonzalez-Mujica et al., 2003).

O extrato metanólico das raízes de Sida cordifolia L. (Malvaceae) apresentou atividade hipoglicêmica e o mecanismo de ação pode ser atribuído à liberação da insulina através do estímulo das células $\beta$ do pâncreas, como no caso das sulfoniluréias (Kanth, Diwan, 1999). O extrato aquoso das partes aéreas de Phyllanthus amarus (Schum) Thonn (Euphorbiaceae) tem sido usado para o tratamento do diabetes melito, porém o estudo desta planta não mostrou efeito hipoglicemiante em pacientes com a diabetes tipo II (Moshi et al., 2001).

O extrato aquoso de Averrhoa bilimbi Linn (Oxalidaceae), da mesma forma que a biguanidina metformina, controlou o aumento da glicose no sangue dos ratos que tiveram o diabetes induzido por estreptozotocina através do decréscimo da atividade da glicose-6-fosfatase no fígado de ratos diabéticos (Pushparaj et al., 2001). A hiperglicemia observada em ratos tratados com estreptozotocina pode levar à formação de peróxido de hidrogênio, o qual gera radicais livres, tais como, $\mathrm{O}^{-2} \mathrm{e} \mathrm{OH}$. 
Estas espécies reativas podem causar a peroxidação de lipídeos, resultando na formação de ácidos graxos hidroperóxido e endoperóxidos, os quais produzem aumento da formação de malonaldeído e tromboxana-B2. O acúmulo da tromboxana-B1 junto com a tromboxana-B2 pode causar a agregação plaquetária e promover a trombose. Desde que a fração aquosa de Averrhoa bilimbi tem a capacidade de reduzir a formação de substâncias tiobarbitúricas reativas, pode impedir a agregação plaquetária e a trombose (Pushparaj et al., 2001).

A atividade antidiabética de algumas especiarias foi avaliada e a canela mostrou ser o produto mais bioativo. Os extratos da canela melhoraram a função dos receptores da insulina, através do receptor insulinoquinase e uma inibição do receptor insulinofosfatase, levando ao aumento do reconhecimento da insulina pelo receptor. Os princípios ativos encontrados neste extrato são polímeros da chalcona (Broadhurst et al., 2000).

Extrato aquoso das folhas secas de Eucalyptus globulus Labill (Myrtaceae) exerceu atividade antidiabética sobre os camundongos que tiveram o diabetes melito induzido por STZ. Entretanto, não apresentou efeito nos camundongos com diabetes induzido por aloxano (World Health Organization, 2002b). O extrato aquoso das folhas de Smallantus sonchifolius Poepp and Endl H. Robinson (Asteraceae) produziu decréscimo significativo no nível de glicose no plasma quando foi administrado por injeção intraperitonial, inibindo a ação hiperglicemiante da STZ, efeito que pode ser atribuído ao fato de esta planta induzir ao aumento na concentração de insulina no plasma (Aybar et al., 2001).

A administração oral do extrato etanólico da casca de Pterocarpus santalinus L. (Fabaceae) foi mais efetivo do que a glibenclamida, antidiabético comercial (Kameswara Rao et al., 2001a). O extrato alcoólico das sementes de trigonella Foenum-graecum L. (Papilionaceae) mostrou inibir a glicosidase intestinal e a liberação de insulina, enquanto que o extrato das folhas de Ocimum sactum afeta a absorção de glicose pelo intestino. Os níveis de glicose dos ratos hiperglicêmicos não decresce nos ratos tratados com Foenum-graecum, mostrando que este extrato não afetou a absorção de glicose pelo intestino, enquanto que os extratos de Pterocarpus marsupium Roxb (Papilionaceae) e de Ocimum sactum podem estar agindo através deste mecanismo (Vikrant et al., 2002). Mecanismos de ação, tais como o efeito de regeneração ou estímulo das células $\beta$ ou efeitos extrapancreáticos são propostos para explicar a ação hipoglicemiante da Momordica charantia, Pterocarpus marsupium e Trigonella foenum greacum (Saxena, Vikram, 2004).
A administração do extrato alcoólico de Aerva lanata (L) Juss. ex. Schultes (Amaranthaceae) reduziu significativamente o nível de açúcar no sangue de ratos que tiveram o diabetes induzido por aloxano, impedindo a perda de peso e reduzindo o aumento da peroxidação de lipídeos (Vetrichelvan, Jegadeesan, 2002).

O nível de glicogênio no fígado pode ser considerado como o melhor marcador para assegurar a atividade hipoglicemiante de qualquer fármaco, pois este indica que a glicose está sendo estocada no fígado na forma de glicogênio através do aumento da glicogênese. A atividade hipoglicemiante dos extratos aquosos e etanólicos de Caesalpinia bonducella F. (Leguminosae) nos modelos de diabetes tipo I e II é atribuída ao aumento no consumo de glicose, a qual é utilizada para a formação do glicogênio com o conseqüente aumento da glicogênese (Chakrabarti et al., 2003). O extrato aquoso da casca de Ceiba pentandra L. Gaertn (Bombacaceae) é atóxico e possui atividade hipoglicemiante (Ladeji et al., 2003).

$\mathrm{O}$ extrato das folhas de Coccinia indica Wight and Arn (Cucurbitaceae) estimula a secreção de insulina nas células $\beta$ existentes em ratos diabéticos. A peroxidação de lipídeos é uma das principais características do diabetes crônico. $\mathrm{O}$ extrato etanólico de $C$. indica possui atividade antioxidante, à qual pode ser atribuída a sua ação protetora sobre a peroxidação de lipídeos. $\mathrm{O}$ aumento da defesa das células pelo efeito antioxidante tem o efeito de proteger contra os danos oxidativos produzidos pelo diabetes induzido pela estreptozotocina (Venkateswaran, Pari, 2003).

O extrato aquoso e alcoólico das raízes de Aporosa lindleyana Baill (Euphorbiaceae) produziu um decréscimo máximo na atividade da glicose em ratos diabéticos, depois de 3 horas da administração oral dos extratos. Os dois extratos também apresentaram atividade hipoglicemiante significativa em ratos normais (Jayakar, Suresh, 2003).

A administração oral do extrato etanólico do fruto de Terminalia pallida Brandis (Combretaceae) apresentou atividade anti-hiperglicemiante em ratos que tiveram o diabetes induzido por aloxano, enquanto nenhum efeito hipoglicemiante foi observado nos ratos normais (Rao et al., 2003). O extrato de Terminalia belerica Roxb (Combretaceae) apresentou maior atividade antioxidante e grande atividade na redução do nível de glicose do soro (Sabu et al., 2002b).

Extrato aquoso de Enicostema littorale Blume (Gentianaceae) é um potente antidiabético natural e este efeito foi atribuído à melhora na sensibilidade da insulina. A ação de baixar o nível de glicose exercida pelo extrato aquoso de Enicostemma littorale foi atribuída ao aumento da 
liberação de insulina. A ação insulinotrópica deste extrato é dependente do canal $\mathrm{K}^{+} \mathrm{ATP}$, porém não requer o influxo de íons cálcio $\left(\mathrm{Ca}^{+2}\right)$ como ocorre nas etapas clássicas para a liberação de insulina. Portanto, este extrato deve conter um príncipio ativo, o qual age somente em condições hiperglicêmicas, causando a liberação de insulina por mecanismo diferente, sendo portanto, candidato potencial para o desenvolvimento de um novo agente terapêutico para pacientes diabéticos (Maroo et al., 2002). Além disso, o extrato diminuiu a concentração de glicose e lipídeos no soro, impedindo a disfunção renal nos ratos diabéticos (Murali et al., 2002; Maroo et al., 2003).

A atividade antidiabética da Helicteres isora Linn (Sterculiaceae) parece ser mediada através da sensibilização da insulina como ocorre com o hipoglicemiante tiazolidinodiona. $\mathrm{O}$ extrato bruto mostrou, também, atividade hipolipidêmica significativa, possuindo potencial para ser usado no tratamento do diabetes tipo II (Chakrabarti et al., 2002). Os extratos aquosos de Rubus fructicosis L. (Rosaceae) exerceu efeito hipoglicêmico acentuado em ratos que tiveram o diabetes induzido por STZ. O mecanismo de ação deste extrato parece ser extra-pancreático e a análise fitoquímica revelou a presença de óleos essenciais, flavonóides e taninos (Jouad et al., 2002).

Extratos dos frutos maduros de Cucurbita ficifolia Bouché (Cucurbitaceae) administrados oralmente e intraperitoneamente produziram efeitos hipoglicemiantes em ratos saudáveis e naqueles que tiveram o diabetes induzido por aloxano. Além disso, a administração oral desta preparação, diariamente, mostrou redução significativamente alta da glicemia, depois de 14 dias de tratamento (Alarcon-Aguilar et al., 2002b). Potentilla fulgens Linn (Rosaceae) pode ser adicionada à crescente lista de plantas hipoglicemiantes e anti-hiperglicemiantes. Provavelmente, esta planta exerce múltiplos efeitos, envolvendo tanto o mecanismo pancreático como o extra-pancreático (Syiem et al., 2002).

O efeito hipoglicemiante do extrato aquoso de Equisetum myriochaetum Schlecht and Cham (Equisetaceae) em pacientes diagnosticados com diabetes do tipo II começou 90 minutos depois da administração da decocção. Os níveis de insulina não mudaram significativamente, o que implica mecanismo de ação diferente ao do hipoglicemiante glibenclamida (Revilla et al., 2002).

$\mathrm{O}$ extrato da semente de Panax ginseng C A. Meyer (Araliaceae) pode oferecer tratamento alternativo para o diabetes do tipo II porque, além de possuir atividade hipoglicemiante, também combate a obesidade, uma das causas do diabetes (Xie et al., 2002). Os glicanos do Panax ginseng estimulam a utilização da glicose hepáti- ca através do aumento da atividade da glicose-6-fosfato desidrogenase e fosfofrutoquinase.

$\mathrm{O}$ extrato de Arachis hypogaea exerceu um efeito hipoglicemiante significativo sobre os ratos que tiveram o diabetes induzido por aloxano (Bilbis et al., 2002).

Extrato das sementes de Securigera securida L. (Fabaceae) reduziu significativamente o nível de glicose no sangue dos camundongos que tiveram o diabetes induzido por aloxano, por um mecanismo diferente daquele exercido pelas sulfoniluréias, as quais não exercem efeito hipoglicemiante nesse tipo de rato (Hosseinzadeh et al., 2002).

$\mathrm{O}$ extrato de Artemisia santonicum L. (Compositae) exerceu um efeito hipoglicemiante em coelhos cujo diabetes foi induzido por aloxano (Korkmaz, Gürdal, 2002). O extrato metanólico da casca de Ficus racemosa Linn (Moraceae) possui um efeito hipoglicemiante similar àquele exercido pela glibenclamida (Rao et al., 2002). A administração oral do extrato aquoso das folhas de Scoparia dulcis L. (Scrophulariaceae) resultou na redução da glicose do sangue, da hemoglobina glicosilada e em aumento na hemoglobina total (Pari, Venkateswaran, 2002).

Extratos aquosos e alcoólicos das folhas de Abutilon indicum L. Sweet (Malvaceae) (Seetharam et al. 2002) e Mimosa pudica Linn. (Mimosaceae) (Amalraj, Ignacimuthu, 2002) apresentaram atividade hipoglicemiante, quando administrados por via oral. Os extratos aquosos e etanólicos das folhas de Gongronema latifolium Benth (Asclepiadaceae) podem exercer sua atividade antidiabética através de suas propriedades antioxidantes. Os extratos aumentaram a atividade da superóxido dismutase e a concentração da glutationa reduzida (Ugochukwu, Babady, 2002). A administração de várias doses do extrato contendo substâncias apolares de Cirsium pascuarense (H. B. K.) Spreng (Compositae) resultou em atividade hipoglicemiante significativa, enquanto que os extratos contendo as substâncias mais polares não produziram mudança nos níveis de açúcar no sangue (Perez Gutierez, 2001). O extrato aquoso de Premna integrifolia Linn (Verbenaceae) mostrou efeito anti-hiperglicemiante devido a possível efeito em retardar a absorção de glicose no trato gastrointestinal ou devido ao aumento no consumo da glicose periférica ou hepática (Alamgir et al., 2001).

Extrato butanólico de Caralluma attenuata Wight (Asclepiadaceae) (Venkatesh et al., 2003) e o extrato aquoso de Spergularia purpurea L. (Caryophyllaceae) (Eddouks et al., 2003; Jouad et al., 2000) apresentaram atividade anti-hiperglicêmica significativa. A atividade antidiabética do suco de Zingiber officinale Rose (Zingiberaceae) na diabetes tipo I, envolve, possivelmen- 
te, os receptores de serotonina (5-hidroxitriptamina) no controle da glicemia. O tratamento com Z. officinale também causou decréscimo nos níveis de colesterol, triglicerídeos e pressão sangüínea (Akhani et al., 2004). Decréscimo significativo da taxa de glicose no sangue e aumento do nível de insulina no plasma foi observado em ratos normais e diabéticos tratados com extrato aquoso das folhas de Boerhaavia diffusa L. (Nyctaginaceae). Este tratamento também resultou em redução significativa da hemoglobina glicosilada e em aumento do nível total de hemoglobina (Pari, Satheesh, 2004). Extrato aquoso das folhas de Annona squamosa Linn (Annonaceae) mostrou atividade antidiabética em ratos que tiveram o diabetes induzido por estreptozotocina/nicotinamida (Shirwaikar et al., 2004). A atividade hipoglicêmica do extrato etanólico das flores de Hibiscus rosa sinensis Linn. (Malvaceae) é comparavel à atividade de glibenclamida, mas não é mediada através da liberação de insulina (Sachdewa, Khemani, 2003). O extrato aquoso da casca do caule de Sclerocarya birrea (A. Rich. Hochst) (Anacardiaceae) mostrou atividade hipoglicêmica para a diabetes do tipo II (Ojewole, 2003).

Alguns testes citotóxicos e in vivo confirmaram a atividade hipoglicêmica do extrato metanólico e validaram o uso popular de Rubus imperialis L. (Rosaceae) como agente antidiabético (Kanegusuku et al., 2002). O mecanismo de ação para a atividade hipoglicêmica do extrato aquoso das folhas de Cassia auriculata Linn (Leguminosae) pode ser atribuído ao aumento do consumo da glicose periférica (Sabu et al., 2002c). A atividade antidiabética do extrato das flores de Cassia auriculata foi mais efetiva do que do fármaco antidiabético glibenclamida. Este extrato causou decréscimo da peroxidação de lipídeos e aumento no nível da glutationa reduzida, superóxido dismutase, catalase, glutationa peroxidase e glutationa- $S$-transferase, mostrando claramente suas propriedades antioxidantes (Pari, Latha, 2003). O efeito antihiperglicemiante do extrato metanólico das flores de Cassia auriculata foi tão potente quanto o fármaco acarbose e ocorreu através da inibição da enzima $\alpha$ glicosidase (Abesundara et al., 2004).

Extrato aquoso do Rhus chineses Mill (Anacardiaceae) inibiu a atividade da $\alpha$-glicosidase, enzima responsável pela digestão de carboidratos a monossacarídeos no processo de absorção intestinal. Este extrato pode exercer efeito antidiabético pela supressão da absorção de carboidrato pelo intestino e, portanto, reduzir o aumento pós-prandial de glicose no sangue (Shim et al., 2003). O extrato de Garcinia cambogia DSER (Hypericaceae) melhorou o metabolismo da glicose desempenhando atividade similar à leptina. A auto-regulação da produção de leptina é acompanhada pelo aumento da produção de insulina (Hayamizu et al., 2003).

As espécies de Opuntia são cactus perenes encontrados em muitas regiões do mundo. A administração oral diária de extratos de Opuntia megacantha Salm Dyck (Cactaceae) a ratos diabéticos e não-diabéticos foi associada à redução da concentração de glicose no plasma sem afetar os níveis de insulina. Constatou-se que estes extratos diminuíram o nível de glicose no plasma sem afetar os níveis de insulina nos ratos diabéticos e não-diabéticos. Estes resultados sugerem, portanto, que o efeito hipoglicemiante observado pode envolver mecanismos de ação que não utilizam a insulina (Bwititi et al., 2000). A espécie Opuntia lindheimeri Englem (Cactaceae) exerceu efeito hipoglicemiante em modelos de porcos diabéticos (Laurenz et al., 2003).

\section{CONSTITUINTES HIPOGLICEMIANTES E MECANISMO DE AÇÃO}

Geralmente as substâncias biologicamente ativas extraídas das plantas são os chamados metabólitos secundários, os quais desempenham papel importante no mecanismo de defesa química. A glicose é a fonte de energia e o precursor mais importante da biossíntese em plantas. Desta forma, a glicose suporta armazenamento e o fornecimento é controlado por hormônios, tanto nas plantas quanto nos animais. O ácido salicílico é um inibidor do crescimento das plantas e um agente hipoglicemiante (Marles, Farnsworth,1995).

Há muitas substâncias extraídas de plantas que reduzem o nível de glicose no sangue e a grande variedade de classes químicas (Tabela II) indica que variedade de mecanismos de ação deve estar envolvida na redução do nível de glicose no sangue. Algumas destas substâncias podem ter potencial terapêutico, enquanto outras podem produzir hipoglicemia como efeito colateral devido à sua toxicidade, especialmente hepatotoxicidade (Ivorra et al., 1989; Pérez Gutiérrez, 2002a; Wang, Ng, 1999; Bae et al., 1999; Pérez Gutiérrez et al., 1998; Lamba et al., 2000).

\section{Terpenóides}

Glicosídeos de triterpenóides e esteróides, os quais são conhecidos como saponinas, são substâncias bioativas presentes em muitas plantas (Rao, Gurfinkel, 2000). Algumas saponinas derivadas de triterpenóides têm ação hipoglicemiante (Connolly, Hill, 2001). O extrato metanólico e a fração solúvel em 1-butanol das folhas de Calendula officinalis L. (Compositae), cultivada como planta ornamental no Egito, mostraram efeito hipo- 
TABELA II - Produtos naturais hipoglicemiantes

\begin{tabular}{lc}
\hline Classe Química & $\begin{array}{c}\text { Número de constituintes } \\
\text { ativos }\end{array}$ \\
\hline Alcalóides & 38 \\
Carboidratos & 66 \\
Cumarinas & 4 \\
Glicosídeos cianogênicos & 1 \\
Flavonóides & 7 \\
Glicopeptídeos & 20 \\
Sais inorgânicos & 3 \\
Iridóides & 4 \\
Lipídios & 6 \\
Peptídeos e aminas & 15 \\
Fenólicos & 4 \\
Fenolpropanóides & 1 \\
Esteróides & 7 \\
Estilbenos & 1 \\
Substâncias sulfúricas & 2 \\
Terpenóides & 17 \\
Vitaminas & 2 \\
Xantonas & 1 \\
\hline
\end{tabular}

Fonte: Marles, Farnsworth, 1995

glicemiantes e gastroprotetivo. Do extrato metanólico das flores de Calêndula officinalis foram isoladas as calendasaponinas $\mathbf{1 A}, \mathbf{1 B}, \mathbf{1 C}, \mathbf{1 D}$ e $\mathbf{1 F}$ (Figura 1), as quais apresentaram um efeito inibitório sobre o aumento do nível de glicose no soro (Yoshikawa et al., 2001). O efeito hipoglicemiante das saponinas é atribuído ao consumo de glicose no intestino (Yoshikawa et al., 2001).

O sesquiterpeno oligoglicosídeo denominado oficinosídeo A 2 (Figura 2), o qual foi isolado das flores da Calendula officinalis egipcia apresentou atividade hipoglicemiante (Marukami et al., 2001).

O efeito hipoglicemiante do extrato metanólico das raízes de Clausena anisata Willd Hook (Rutaceae) pode ser, pelo menos parcialmente, atribuído aos terpenóides e cumarinas presentes nesta planta. O efeito dos terpenóides parece envolver a estimulação das células $\beta$-pancreáticas com a subseqüente secreção da insulina e o mecanismo de ação hipoglicemiante das cumarinas provavelmente envolve hepatotoxicidade (Ojewole, 2002). Dois triterpenos isolados da Agarista mexicana possuem potencial antidiabético (Figura 3). O 12-urseno 3 exerce efeito hipoglicêmico mais lento e menos efetivo do que a tolbutamida, enquanto que o 23,24-dimetil-24-etilestigmast-25-eno 4 mostrou ser mais efetivo do que a tolbutamida (Perez-Gutiérez, Vargas, 2002b). Os ácidos oleanólico e ursólico mostraram atividade hipoglice-

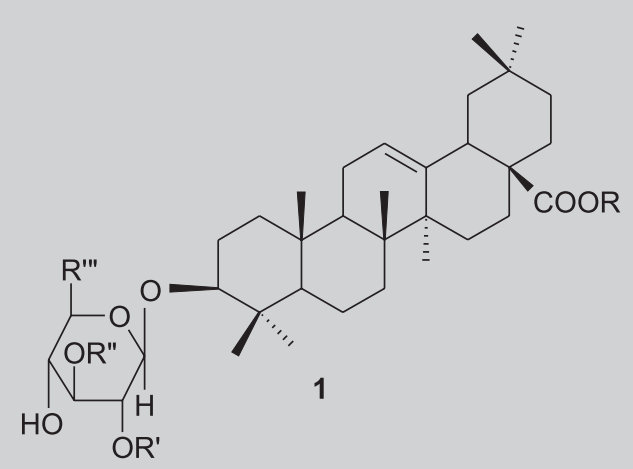

1A: $R=$ Glc, R'= Glc, R"= Gal, R'"= $\mathrm{COOH}$

1B: $R=H, R^{\prime}=G l c, R^{\prime \prime}=G a l, R^{\prime \prime}=\mathrm{COOH}$

1C: $R=G l c, R^{\prime}=H, R^{\prime \prime}=G a l, R^{\prime \prime}=\mathrm{COOH}$

1D: $R=H, R^{\prime}=H, R^{\prime \prime}=\mathrm{Gal}, \mathrm{R}^{\prime \prime}=\mathrm{COOH}$

1F: $R=H, R^{\prime}=H, R^{\prime \prime}=H, R^{\prime \prime}=\mathrm{COOH}$

FIGURA 1 - Saponinas isoladas das flores de Calendula officinalis.

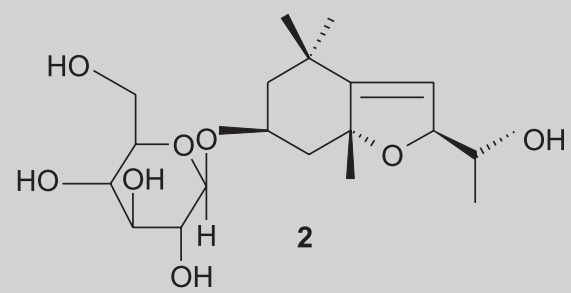

FIGURA 2 - Sesquiterpeno oligoglicosídeo das flores de Calendula officinalis.

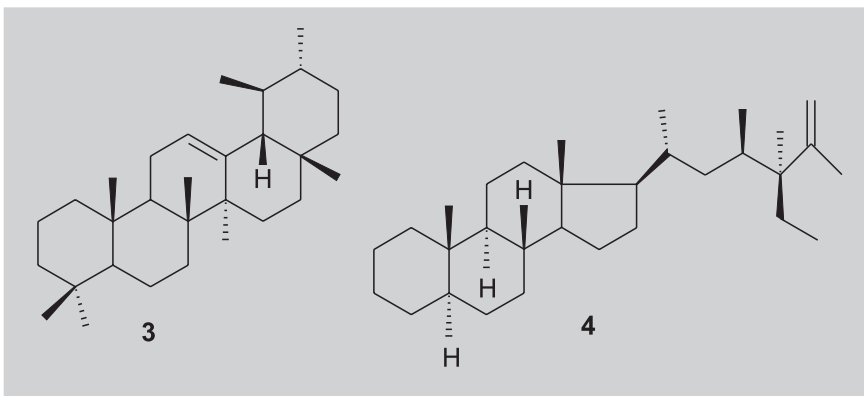

FIGURA 3 - Triterpenos isolados da Agarista mexicana.

miantes, além das atividades cardiovascular, anti-hiperlipidêmica e antioxidante (Somova et al., 2003).

O constituinte principal isolado da casca do Croton cajucara Benth (Euphorbiaceae), a trans-desidrocrotonina, classificada como uma lactona tipo clerodano diterpeno, exibiu atividade hipoglicemiante em camundongos, portanto apresenta potencial antidiabético (Silva et al., 2001; Agner et al., 2001). 


\section{Alcalóides}

Multiflorina, substância isolada de plantas leguminosas, exerce efeito hipoglicemiante. Esta substância tem conjugação tipo enaminona no anel $\mathrm{A}$, a qual é rara em alcalóides lupínicos. $\mathrm{O}$ efeito hipoglicêmico do $(7 R$, 9aS)-7-fenil-octaidroquinolizin-2-ona foi aproximadamente quatro vezes maior do que o da multiflorina. Este resultado mostrou que as substâncias que possuem o anel quinolizidin-2-ona como estrutura básica, tem potencial como fármaco antidiabética (Kubo et al., 2000). Derivados da criptolepina 5 (Figura 4), um membro da família dos alcalóides indoloquinolinas, possuem atividade antihiperglicemiantes (Bierer et al., 1998).

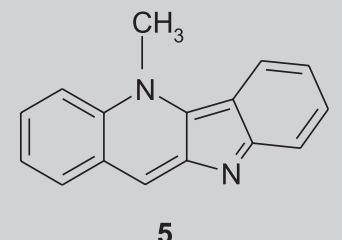

FIGURA 4 - Criptolepina.

\section{Cumarinas}

Do extrato aquoso-etanólico das partes aeréas da planta Teramnus labialis (Roxb.) Benth. (Fabaceae) foi obtida uma fração contendo mistura de cumarinas. A cumarina mais abundante encontrada nesta fração ativa foi identificada como fraxidina 6 (Figura 5). As cumarinas possuem atividade hipoglicemiante e efeito inibitório sobre a atividade da enzima aldose redutase e sobre a agregação plaquetária, as quais são consideradas como as causas das complicações diabéticas (Fort et al., 2000a).

\section{Flavonóides}

Os flavonóides são um grupo de pigmentos naturais, amplamente distribuídos em angiospermas e ginospermas. Estão presentes em frutas, vegetais, cereais, raízes, folhas e caules. São atribuídas aos flavonóides diversas atividades biológicas, tais como cardioprotetiva e hipoglicemiante. Alguns flavonóides aumentam a liberação de insulina das ilhotas isoladas de Langerhans de forma dependente de sua concentração (Koshy, Vijayslakshmi et al., 2001).

Os extratos brutos das folhas de Brickellia veronicaefolia Gray (Asteraceae) produziram efeito hipoglicemiante em ratos que tiveram o diabetes induzido

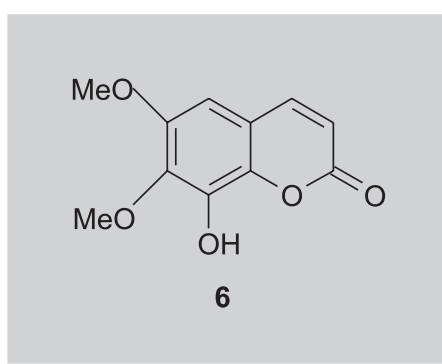

FIGURA 5 - Fraxidina.

por aloxano. A partir destes extratos foi isolada a 5,7,3'triidroxi-3,6,4'-trimetoxiflavona, a qual produziu um efeito hipoglicêmico significativo, porém menos efetivo do que a tolbutamida (Perez et al., 2000a).

Os flavonóides encontrados no extrato aquoso de Ajuga iva (L.) Schreber (Labiatae) apresentaram atividade hipoglicemiante (Hilaly, Lyoussi, 2002), assim como os flavonóides rutina e isoquercetina encontrados no extrato aquoso de Phyllanthus sellowianus L. (Euphorbiaceae) (Hnatyszyn et al., 2002). Os esteróides e flavonóides encontrados no extrato metanólico das sementes de Punica granatum Linn (Punicaceae) também apresentaram atividade hipoglicemiante (Das et al., 2001).

A flavona isoorientina 7 (Figura 6) e o ácido 3 cafeoilquínico (ácido clorogênico) extraídos da Cecropia obtusifolia Bertol (Cecropiaceae) exerceram efeito hipoglicemiante (Andrade-Cetto, Wiedenfeld, 2001). Os flavonóides da Suaeda fruticosa L. (Chenopodiaceae) apresentaram atividade hipoglicemiante e reduziram, também, a taxa de colesterol no sangue (Benwalhoud et al., 2001). Três derivados de canferol glicosilados e um cafeil glicosídeo, isolados do extrato aquoso e butanólico das partes aéreas do Equisetum myriochaetum L. (Equisetaceae) exerceram atividade hipoglicemiante em ratos que tiveram o diabetes induzido por STZ (Andrade Cetto et al., 2000).

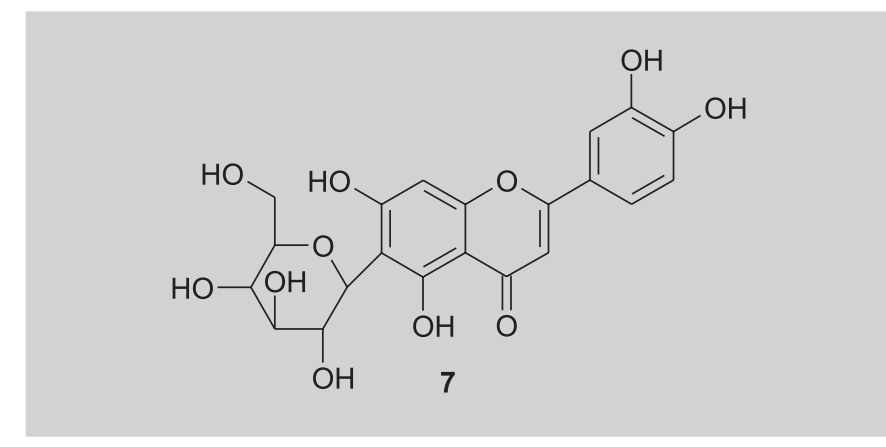

FIGURA 6 - Flavonóide isoorientina. 
Na Medicina Oriental, o rizoma da Anemarrhena asphodeloides L. (Liliaceae) tem sido usado para tratar os sintomas de poliúria e polidipsia em pacientes diabéticos. Estudos feitos em cobaias indicaram que o mecanismo de ação desta planta pode ser atribuído à melhora na função do receptor, com aumento do reconhecimento da insulina por este. $\mathrm{O}$ efeito antidiabético foi atribuído a duas substâncias, a mangiferina 8 e a mangiferina-7- $O-\beta$-glicosídeo 9 (Figura 7), embora se conheça pouco sobre a atividade antidiabética das xantonas (Miura et al., 2001a). A mangiferina exerceu atividade antidiabética através do decréscimo da resistência do receptor à insulina (Miura et al., 2001b). A substância polifenólica mangiferina pode ser usada na prevenção do câncer, desordens autoimunes, aterosclerose e doença coronária (Leiro et al., 2003).

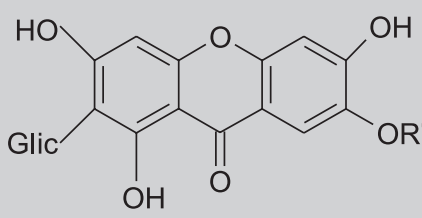

8 Mangiferina $\mathrm{R}^{\prime}=\mathrm{H}$

9 Mangiferina-7-O- $\beta$-glicosídeo

$\mathrm{R}^{\prime}=\mathrm{Glic}=\beta-\mathrm{D}-$ glicopiranosil

FIGURA 7 - Mangiferina e seu glicosídeo.

\section{Substâncias fenólicas}

O ácido isoferúlico extraído do rizoma da Cimicifuga dahurica Maxim. (Ranunculaceae) apresentou atividade hipoglicemiante in vivo para os casos de diabetes tipo I (Liu et al., 1999). O ácido 4-hidroxibenzóico isolado do extrato aquoso das raízes de Pandanus odorus Ridl (Pandanaceae) mostrou efeito hipoglicemiante em ratos normais, aumentando o nível de insulina no soro e o conteúdo de glicogênio no fígado (Peungvicha et al., 1998). O bacuquiol 10 (Figura 8) foi isolado do extrato de Otholobium pubenscens L. (Fabaceae) e reduziu significativamente a taxa de glicose e triglicerídeos no sangue (Krenisky et al., 1999).

O ácido benzóico e seus derivados inibiram a ação da enzima insulinase e aumentaram o efeito da insulina (Marles, Farnsworth, 1995; Peungvicha et al., 1998). Polifenóis, tais como, galocatequina, epicatequina, epigalocatequina e o galato de epigalocatequina possuem atividade antidiabética (Sabu et al., 2002a). Os dois princípios ativos antidiabéticos marsupsina e pteroestilbeno foram

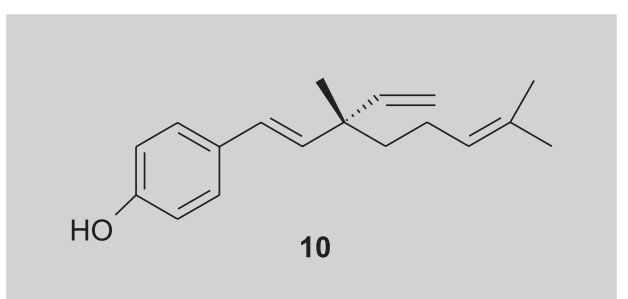

FIGURA 8 - Bakuquiol.

isolados da casca de Pterocarpus marsupium. O pteroestilbeno pode ser considerado um marcador químico confiável para a avaliação do controle de qualidade do Pterocarpus marsupium (Mallavadhani, Sahu, 2003). Substâncias polifenólicas reduzem a glicemia (Al-Awwadi et al., 2004).

\section{Outros constituintes hipoglicemiantes}

A atividade hipoglicemiante do extrato das sementes de Urtica pilulifera L. (Urticaceae) é atribuída à presença de lecitinas, glicoproteínas que se ligam especificamente resíduos de açúcar. A ação hipoglicemiante da lecitina corresponde ao aumento tanto da secreção de insulina através das células $\beta$, quanto da liberação da insulina de seus receptores, podendo, também, mimetizar a ação da insulina através da interação com os resíduos glicoproteína dos receptores de insulina. As lecitinas podem, também, aumentar a secreção da mucosa intestinal modificando a absorção da glicose (Kavalali et al., 2003).

$\mathrm{O}$ extrato aquoso das frutas de Parmentiera edulis DC. (Bignoniaceae) tem sido usado por muito tempo no tratamento do diabetes melito. As substâncias presentes no extrato reduziram a taxa de glicose no sangue de camundongos que tiveram o diabetes induzido por aloxano. Do extrato clorofórmico dos frutos secos de Parmentiera edulis foi isolado um guaianolídeo, o lactucin-8-Ometilacrilato, com atividade hipoglicêmica (Perez et al., 2000b)

A capsaicina 11 (Figura 9) associada a outros capsinocóides é um dos principais constituintes ativos do fruto do Capsicum spp, conhecido como pimenta. Está sendo usada no tratamento da neuropatia dolorosa dos diabéticos (Tolan et al., 2001). Aumentou a taxa de insulina no plasma, o que poderia ser devido ao aumento da secreção de insulina ou ao retardo na quebra de sua molécula. A elevação da taxa de insulina no plasma reduziu a sensibilidade das células-alvo (receptor) e desta forma houve decréscimo do número de receptores por célula. Esta auto-regulação é vista como medida protetiva adotada pelas células, uma vez que, no caso de hiperinsulinemia, isto poderia, por outro lado, 
causar consumo rápido da glicose do sangue, resultando em coma hipoglicêmico. A capsaicina, portanto, afeta a taxa de açúcares no sangue principalmente através da elevação do nível de insulina no plasma. Embora haja redução no número de receptores para a insulina, o efeito líquido total é a hipoglicemia (Tolan et al., 2001).

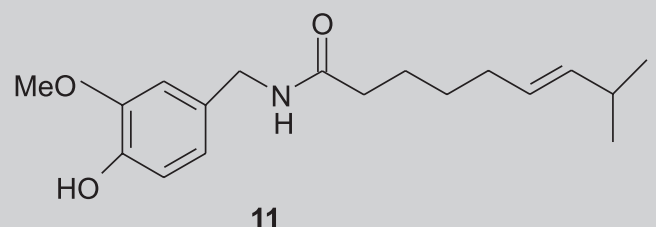

11

FIGURA 9 - Capsaicina.

Polissacarídeos, tais como o cacalol 12 e a maturinona 13 (Figura 10) têm sido reportados como substâncias hipoglicemiantes (Alarcon, Aguilar et al., 2000a,b; 2002a).

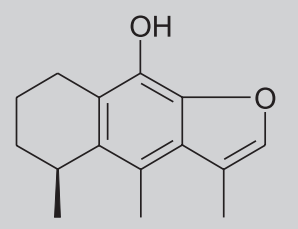

12

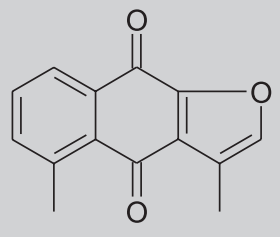

13
FIGURA 10 - Cacalol e maturinona.

Do extrato etanólico das folhas e caules da planta africana Pycnanthus angolensis (Welw.) Warb (Myristicaceae) foram isoladas as picnantuquinonas 14A e 14B (Figura 11), as quais são os primeiros representantes de um novo esqueleto terpenóide tipo quinona, que possuem atividade anti-hiperglicemiante significativa (Fort et al., 2000b).

Um dibenzofurano prenilado, o aquirofurano 15 (Figura 12), foi isolado do extrato metanólico de Achyrocline satureioides (Lam) DC. (Compositae) e exibiu atividade anti-hiperglicemiante para o diabetes do tipo II, com a redução significativa do nível de glicose no sangue. Esta espécie é muito usada como planta medicinal na América do Sul, onde é conhecida como marcela (Carney et al., 2002).

Extratos das folhas de Stevia rebaudiana (bertoni) Hemsl (Asteraceae) têm sido usados no Paraguai e Brasil para o tratamento do diabetes. Destes extratos foi isolado um esteviosídeo, o que apresentou efeitos anti-

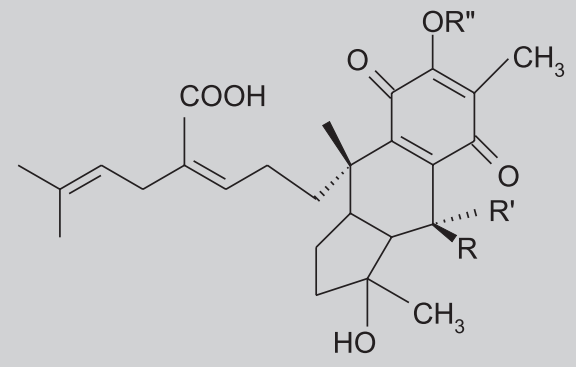

14A: $\mathrm{R}=\mathrm{R}^{\prime \prime}=\mathrm{H}, \mathrm{R}^{\prime}=\mathrm{OH}$

14B: $R^{\prime}=R^{\prime \prime}=H, R=O H$

FIGURA 11 - Terpenóides tipo quinona.

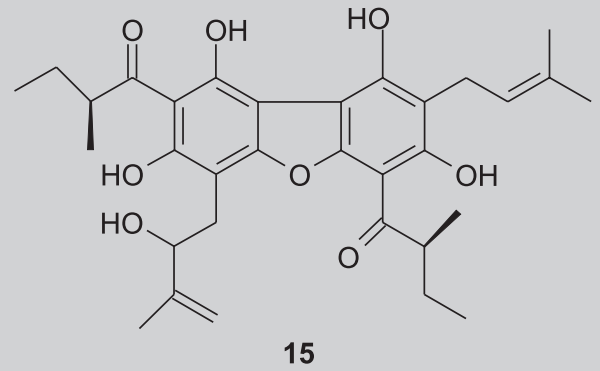

FIGURA 12 - Dibenzofurano prenilado.

hiperglicêmicos, insulinotrópicos, assim como glucagonostáticos em ratos diabéticos (Jepresen et al., 2002).

A inibição da ação da enzima dipeptidilpeptidase IV pode tornar-se a principal terapia no tratamento da diabetes tipo II. O 1-[[(3-hidroxi-1-adamantil)amino]acetil]-2-ciano(S)-pirrolidina é um inibidor da dipeptidilpeptidase IV potente, seletivo e oralmente disponível com propriedades antihiperglicemiantes (Vilhauer et al., 2003). Derivados de cadeia longa de carbamoil aminocarnitina são fármacos potenciais antidiabéticos, que inibem reversivelmente a enzima carnitina palmitoiltransferase (Giannessi et al., 2003). A atividade antidiabética do extrato das folhas de Cogniauxia podoleana Baillon (Cucurbitaceae) não pode ser atribuída apenas à presença de flavonóides que estão contidos na fração obtida com éter etílico, devido ao fato de esta fração conter outras substâncias, tais como aminoácidos e carboidratos, entre outros (Diatewa et al., 2004).

A 2,5-diidroxibenzilideno aminoguanidina é um análogo estrutural do fármaco antidiabético aminoguanidina e é exemplo de uma substância que protege os ratos diabéticos de oxidação das lipoproteínas, um processo que ocorre nas condições de "stress" oxidativo, característico do diabetes melito (Korytar et al., 2003). A 3-nitro-2'- 
benziloxichalcona estimulou o consumo de glicose e aumentou a secreção de insulina de maneira dependente da concentração (Kamei et al., 2003). Os ácidos retinóides (2E,4E,6Z)-7-(2-alcoxi-3,5-dialquilbenzeno)-3-metilocta2,4,6-trienóicos mostraram atividade antidiabética nos modelos de diabetes tipo II (Michellys et al., 2003). Latucaina $\mathrm{C}$, uma lactona sesquiterpênica, e a lactucasida, uma lignana furofurânica, mostraram atividade antidiabética significativa (Hou et al., 2003). Escropoliosídeo-D-2, um glicosídeo iridóide extraído das folhas de Scropularia deserti Del (Scrophulariaceae) apresentou atividade antidiabética significativa. Óleos essenciais, tais como canferídeo, alpinina, galangina e cinamato de metila apresentaram atividade hipoglicemiante (Ahmed et al., 2003).

A atividade antidiabética de pirazóis substituídos ácidos 4-carboxílicos 16 (Figura 13) - foi determinada através de testes realizados em ratos Wistar com diabetes tipo II. Os pirázois apresentaram atividade hipoglicemiante in vivo, provavelmente através da inibição da atividade do canal ATP- $\mathrm{K}^{+}$das membranas das células $\beta$-pancreáticas, o que induz a produção de insulina (Cottineau et al., 2002). Os derivados de $1 H$ pirróis,2-metil-3,4,5-trifenil-substituídos mostraram inibição da hiperglicemia pós-prandial em ratos normais e diminuíram a taxa de glicose no plasma dos ratos com diabetes induzido por estreptozotocina (Goel et al., 2004). As piridinas e purinas que contêm o grupo 2,4tiazolidinodiona apresentaram atividade hipoglicêmica (Kim et al., 2004). Desde a descoberta de substâncias similares à insulina bovina em plantas tem-se estimulado a caracterização destas proteínas e elucidação das suas funções. Uma proteína com massa molecular similar e mesma seqüência de aminoácidos que a insulina bovina foi encontrada nos frutos de Vigna unguiculata (L.) Walp (Papilionaceae) (Cowpea) (Venancio et al., 2003).

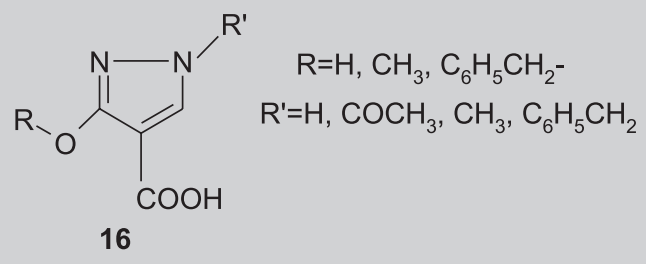

FIGURA 13 - Pirazóis com propriedade antidiabética

\section{CONCLUSÃO}

Esta revisão bibliográfica acrescentou mais informações àquelas já existentes nas referências publicadas an- teriormente, uma vez que existem muitas plantas que apresentam efeito hipoglicemiante. Os estudos feitos com as plantas medicinais usadas, tradicionalmente, no tratamento do diabetes melito, demonstraram que em sua maioria estas possuem característica hipoglicemiante, confirmando a utilização como antidiabético na medicina popular. Muitas plantas exercem efeito hipoglicemiante, atribuído a vários mecanismos de ação, porém nem todas são terapeuticamente úteis. Algumas plantas utilizadas podem ser tóxicas, enfatizando a necessidade de encontrar aquelas que possam oferecer eficácia terapêutica e saúde. Há muitas substâncias extraídas de plantas que reduzem o nível de glicose no sangue. A grande diversidade de classes químicas indica que variedade de mecanismos de ação deve estar envolvida na redução do nível de glicose no sangue. Algumas destas substâncias podem ter potencial terapêutico, enquanto outras podem produzir hipoglicemia como efeito colateral devido à sua toxicidade, especialmente hepatotoxicidade.

\section{ABSTRACT}

\section{Diabetes mellitus: hypoglicemic plants and natural active principles}

Diabetes mellitus comprises a group of ethiologically and clinically heterogeneous disorders with a common set of symptoms: excessive thirst and hunger, muscular weakness, weight loss, excessive urination and elevation of the blood glucose level among others. There has been a striking emergence of non-insulindependent diabetes mellitus as a major health problem in populations undergoing modernization of life-style, both in developed and underdeveloped nations. Many species of plants have been used ethnopharmacologically or experimentally to treat symptons of diabetes mellitus. The high percentage of active plants probably reflects, at least in part, the great variety of possible active constituents and mechanisms of action. The wide diversity of chemical classes indicate a variety of mechanisms must be involved in the lowering of the blood glucose level. Some of these compounds may have therapeutic potential, while others may produce hypoglycemia as a side-effect of their toxicity, specially hepatotoxicity. The present article is an actualized review of hypoglicemic medicinal plants and their active constituents.

UNITERMS: Diabetes mellitus. Hypoglicemic plants. Hypoglicemic activity of compounds. 


\section{AGRADECIMENTOS}

Ao Conselho Nacional de Desenvolvimento Científico e Tecnológico (CNPq) e à Fundação de Amparo à Pesquisa do Estado de São Paulo (FAPESP).

\section{REFERÊNCIAS BIBLIOGRÁFICAS}

ABESUNDARA, K. J. M.; MATSUI, T.; MATSUMOTO, K. Alpha-glucosidase inhibitory activity of some Sri Lanka plant extracts, one of which, Cassia auriculata, exerts a strong anti-hyperglycemic effect in rats comparable to the therapeutic drug acarbose. J. Agric. Food Chem., v. 52, p. 2541-2545, 2004.

AGNER, A. R.; MACIEL, M. A.; PINTO, A. C.; CÓLUS, I. M. Antigenotoxicity of trans-dehydrocrotonin, a clerodane diterpene from Croton cajucara. Planta Medica, 67, 815-819, 2001.

AHMED, B.; AL-REHAILY, A. J.; AL-HOWIRINY, T. A.; EL-SAYED, K. A.; AHMAD, M. S. Scropolioside-D-2 and harpagoside-B: two new iridoid glycosides from Scrophularia deserti and their antidiabetic and antiinflammatory activity. Biol. Pharm. Bull., v. 26, p. 462467, 2003.

AKHANI, S. P.; VISHWAKARMA, S. L.; GOYAL, R. K. Anti-diabetic activity of Zingiber officinale in streptozotocin-induced type I diabetic rats. J. Pharm. Pharmacol., v. 56, p. 101-105, 2004.

AKHTAR, M. S.; KHAN, M. A.; MALIK, M. T. Hypoglycaemic activity of Alpinia galanga rhizome and its extracts in rabbits. Fitoterapia, v. 73, p. 623-628, 2002.

ALAMGIR, M.; ROKEYA, B.; HANNAN, J. M. A.; CHOUDHURI, M. S. K. The effect of Premma integrifolia Linn (Verbenaceae) on blood glucose in streptozotocin induced type 1 and type 2 diabetic rats. Pharmazie, v. 56, p. 903-904, 2001.

ALARCON AGUILAR, F. J.; JIMENEZ ESTRADA, M.; REYES CHILPA, R.; GONZALEZ PAREDES, B.; CONTRERAS WEBER, C. C.; ROMAN RAMOS, R. Hypoglycemic activity of root water decoction, sesquiterpenoids, and one polysaccharide fraction from Psacalium decompositum in mice. J. Ethnopharmacol., v. 69, p. 207-215, 2000a.
ALARCON AGUILAR, F.J.; JIMENEZ ESTRADA, M.; REYES CHILPA, R.; ROMAN RAMOS, R. Hypoglycemic effect of extracts and fractions from Psacalium decompositum in healthy and alloxan-diabetic mice. J. Ethnopharmacol., v. 72, p. 21 - 27, 2000b.

ALARCON AGUILAR, F. J.; ROMAN RAMOS, R.; FLORES SAENZ, J. L.; AGUIRRE GARCIA, F. Investigation on the hypoglycaemic effects of extracts of four Mexican medicinal plants in normal and alloxandiabetic mice. Phythoter. Res., v. 16, p. 383-386, 2002 a.

ALARCON AGUILAR, F. J.; HERNANDEZ-GALÍCIA, E.; CAMPOS-SEPULVEDA, A. E.; XOLALPAMOLINA, S.; RIVAS-VILCHIS, J. F.; VAZQUEZCARRILLO, L. I.; ROMAN-RAMOS, R. Evaluation of hypoglycemic effect of Cucurbita ficifolia Bouché (Cucurbitaceae) in different experimental models. $J$. Ethnopharmacol., v. 82, p. 185-189, 2002 b.

AL-AWWADI, N.; AZAY, J.; POUCHERET, P.; CASSANAS, G.; KROSNIAK, M.; AUGER, C.; GASC, F.; ROUANET, J. M.; CROS, G.; TEISSEDRE, P. L. Antidiabetic activity of red wine polyphenolic extract, ethanol or both in streptozotocin-treated rats. J. Agric. Food Chem., v. 52, p. 1008-1016, 2004.

AL-KHALILI, L.; CHIBALIN, A. V.; KANNISTO, K.; ZHANG, B. B.; PERMERT, J.; HOLMAN, G. D.; EHRENBORG, E.; DING, V. D. H.; ZIERATH, J. R.; KROOK, A. Insulin action in cultures human skeletal muscle cells during differentiation: assessment of cell surface GLUT4 and GLUT1 content. Cell Mol. Life Sci., v. 60, p. 991-998, 2003.

AMALRAJ, T.; IGNACIMUTHU, S. Hyperglycemic effect of leaves of Mimosa pudica Linn. Fitoterapia, v. 73, p. 351-352, 2002.

ANDRADE-CETTO, A.; WIEDENFELD, H.; REVILLA, M. C.; SERGIO, I. A. Hypoglycemic effect of Equisetum myriochaetum aerial parts on streptozotocin diabetic rats. J. Ethnopharmacol., v. 72, p. 129-133, 2000.

ANDRADE-CETTO, A.; WIEDENFELD, H. Hypoglycemic effect of Cecropia obtusifolia on streptozotocin diabetic rats. J. Etnopharmacol., v. 78, p. 145-149, 2001. 
ANKLI, A.; HEINRICH, M.; BORK, P.; WOLFRAM, L.; BAUERFEIND, P.; BRUN, R.; SCHMID, C.; WEISS, C.; BRUGGISSER, R.; GERTSCH, J.; WASESCHA, M.; STICHER, O. Yucatec Mayan medicinal plants: evaluation based on indigenous uses. $J$. Ethnopharmacol., v. 79, p. 43-52, 2002.

AYBAR, M. J.; SÁNCHEZ RIERA, A. N.; GRAU, A.; SÁNCHEZ, S. S. Hypoglycemic effect of the water extract of Smallantus sonchifolius (Yacon) leaves in normal and diabetic rats. J. Ethnopharmacol., v. 74, p. 125-132, 2001.

BAE, E. A.; HAN, M. J.; LEE, K. T.; CHOI, J. W.; PARK, H. J.; KIM, D. H. Metabolism of 6"-O-xylosyltectoridin and tectoridin by human intestinal bacteria and their hypoglicemic and in vitro cytotoxic activities. Biol. Pharm. Bull., v. 22, p. 1314-1318, 1999.

BALUCHNEJADMOJARAD, T.; ROGHANI, M.; HOMAYOUNFAR, H.; HOSSEINI, M. Beneficial effect of aqueous garlic extract on the vascular reactivity of streptozotocin diabetic rats. J. Ethnopharmacol., v. 85, p. 139-144, 2003.

BECK, A.; MOESCHEL, K.; DEEG, M.; HÄRING, H. U.; VOELTER, W. SCHLEICHER, E. D.; LEHMANN, R. Identification of an in vitro insulin receptor substrate-1 phosphorylation site by negative-ion muLC/ES-API-CIDMS hybrid scan technique. J. Am. Soc. Mass Spectrom., v. 14, p. 401-405, 2003.

BENNETT, P. H. Diabetes in developing countries and unusual populations. In: MANN, J. I.; PYÖRÄLÄ, K.; TEUSCHER, A., (Eds.). Diabetes in Epidemiological Perspective. Churchill Livingstone, Edinburgh, p. 43-57, 1983.

BENWALHOUD, M.; JOUAD, H.; EDDOUKS, M.; LYOUSSI, B. Hypoglycemic effect of Suaeda fruticosa in streptozotocin-induced diabetic rats. $J$. Ethnopharmacol., v. 76, p. 35-38, 2001.

BERNE, R. M.; GENUTH, S. M. Fisiologia. 4 ed. Rio de Janeiro: Guanabara Koogan, 2000. p. 190.
BIERER, D. E.; DUBENKO, L. G.; ZHANG, P.; LU, Q.; IMBACK, P. A.; GAROFALO, A. W.; PHUAN, P. W.; FORT, D. M.; LITVAK, J.; GERBER, R. E.; SLOAN, B.; LUO, J.; COOPER, R. REAVEN, G. M. Antihyperglycemic activities of cryptolepine analogues: na ethnobotanical lead structure isolated from Cryptolepis sanguinolenta.J. Med. Chem., v. 41, p. 2754-2764, 1998.

BILBIS, L. S.; SHEHU, R. A.; ABUBAKAR, M. G. Hypoglycemic and hypolipidemic effects of aqueous extract of Arachis hypogaea in normal and alloxaninduced diabetic rats. Phytomedicine, v. 9, p. 553-555, 2002.

BRANSOME, E. D. Financing the care of diabetes mellitus in the U.S. Diabetes Care, v. 15, p. 1-5, 1992.

BROADHURST, C. L.; POLANSKY, M. M.; ANDERSON, R, A. Insulin-like biological activity of culinary and medicinal plant aqueous extracts in vitro. $J$. Agric. Food Chem., v. 48, p. 849-852, 2000.

BWITITI, P.; MUSABAYANE, C. T.; NHACHI, C. F. B. Effects of Opuntia megacantha on blood glucose and kidney function in streptozotocin diabetic rats. $J$. Ethnopharmacol., v. 69, p. 247-252, 2000.

CARNEY, J. R.; KRENISKY, J. M.; WILLIAMSON, R. T.; LUO, J. Achyrofuran, a new antihyperglycemic dibenzofuran from the south americam medicinal plant Achyrocline satureioides. J. Nat. Prod., v. 65, p. $203-$ 207, 2002.

CHAKRABARTI, S.; BISWAS, T. K.; ROKEYA, B.; ALI, L.; MOSIHUZZAMAN, M.; NAHAR, N.; AZAD KHAN, A. K.; MUKHERJEE, B. Advanced studies on the hypoglicemic effect of Caesalpinia bonducella $\mathrm{F}$. in type 1 and 2 diabetes in long Evans rats. $J$. Ethnopharmacol., v. 84, p. 41-46, 2003.

CHAKRABARTI, R.; VIKRAMADITHYAN, R. K.; MULLANGI, R.; SHARMA, V. M.; JAGADHESHAN, H.; RAO, Y. N.; SAIRAM, P.; RAJAGOPALAN, R. Antidiabetic and hypolipidemic activity of Helicteres isora in animal models. J. Ethnopharmacol., v. 81, p. 343-349, 2002.

CHATTOPADHAY, R. R. Possible mechanism of antihyperglycemic effect of Azadirachta indica leaf extract. J. Ehnopharmacol., v. 67, p. 373-376, 1999. 
CLAYTON, H. A.; JAMES, R. F.; LONDON, N. J. Islet microencapsulation: a review. Acta Diabetologica, v. 30, p. 181-189, 1993.

CONNOLLY, J. D.; HILL, R. A. Triterpenoids. Nat. Prod. Report, v. 18, p. 560-578, 2001.

COTTINEAU, B.; TOTO, P.; MAROT, C.; PIPAUD, A.; CHENAULT, J. Synthesis and hypoglycemic evaluation of substituted pyrazole-4-carboxylic acids. Bioorg. Med. Chem. Lett., v. 12, p. 2105-2108, 2002.

DAS, A. K.; MANDAL, S. C.; BANERJEE, S. K.; SINHA, S.; SAHA, B. P.; PAL, M. Studies on the hypoglycaemic activity of Punica granatum seed in Streptozotocin induced diabetic rats. Phytother. Res., v. 15, p. 628-629, 2001.

DIATEWA, M.; SAMBA, C. B.; ASSAH, T. C. H.; ABENA, A. A. Hypoglycemic and antihyperglycemic effects of diethyl ether fraction isolated from the aqueous extract of the leaves of Cogniauxia podoleana Baillon in normal and alloxan-induced diabetic rats. $J$. Ethnopharmacol., v. 92, p. 229-232, 2004.

EDDOUKS, M.; MAGHRANI, M.; LEMHADRI, A.; OUAHIDI, M-L.; JOUAD, H. Ethnopharmacological survey of medicinal plants used for the treatment of diabetes mellitus, hypertension and cardiac diseases in the southeast region of Morocco (Tafilalet). $J$. Ethnopharmacol., v. 82, p. 97-103, 2002.

EDDOUKS, M.; JOUAD, H.; MAGHRANI, M.; LEMHADRI, A.; BURCELIN, R. Inhibition of endogenous glucose productoon accounts for hypoglycemic effect of Spergularia purpurea in streptozotocin mice. Phytomedicine, v. 10, p. 594-599, 2003.

ELDER, C. Ayurveda for diabetes mellitus: a review of the biomedical literature. Altern. Ther. Health Med., v. 10, p. 44-50, 2004.

ERNST, E. Plants with hipoglycemic activity in humans. Phytomedicine, v. 4, p. 73-78, 1997.

FORT, D. M.; RAO, K, JOLAD, S. D.; LUO, J.; CARLSON, T. J.; KING, S. R. Antihyperglycemic activity of Teramnus labialis (Fabaceae). Phytomedicine, v. 6, p. 465-467, 2000a.
FORT, D. M.; UBILLAS, R. P.; MENDEZ, C. D.; JOLAD, S. D.; INMAN, W. D.; CARNEY, J. R.; CHEN, J. L.; IANIRO, T. T.; HASBUN, C.; BRUENING, R. C.; LUO, J.; REED, M. J.; IWU, M.; CARLSON, T. J.; KING, S. R.; BIERER, D. E.; COOPER, R. Novel antihyperglycemic terpenoid-quinones from Pycnanthus angolensis. J. Org. Chem., v. 65, p. 6534-6539, 2000b.

GIANNESSI, F.; PESSOTTO, P.; TASSONI, E.; CHIODI, P.; CONTI, R.; De ANGELIS, F.; DELL'UOMO, N.; CATINI, R.; DEIAS, R.; TINTI, M. O.; CARMINATI, P.; ARDUINI, A. Discovery of a long-chain carbamoyl aminocarnitine derivative, a reversible carnitine palmitoyltransferase inhibitor with antiketonic and antidiabetic activity. J. Med. Chem., v. 46, p.303-309, 2003.

GODOY, P. Pâncreas Endócrino. In: BOGLIOLO, L. Patologia. 6. ed. Rio de Janeiro: Guanabara Koogan, 2000. p. 1004-1008.

GOEL, A.; AGARWAL, N.; SINGH, F. V.; SHARON, A.; TIWARI, P.; DIXIT, M.; PRATAP, R.; SRIVASTAVA, A. K.; MAULIK, P. R.; RAM, V. J. Antihyperglicemic activity of 2-methyl-3,4,5-triaryl-1H-pyrroles in SLM and STZ models. Bioorg. Med. Chem. Lett., v. 14, p. 10891092, 2004.

GONZALEZ-MUJICA, F.; MOTTA, N.; MÁRQUEZ, A. H.; CAPOTE-ZULUETA, J. Effects of Bauhinia megalandra aqueous leaf extract on intestinal glucose absorption and uptake by enterocyte brush border membrane vesicles. Fitoterapia, v. 74, p. 84-90, 2003.

GROVER, J. K.; VATS, V.; RATHI, S.S.; DAWAR, R. Traditional Indian anti-diabetic plants Attenuate progression of renal damage in streptozotocin induced diabetic mice. J. Ethnopharmacol., v. 76, p. 233-236, 2001.

GROVER, J. K.; YADAV, S.; VATS, V. Hypoglycemic and antihyperglycemic effect of Brassica juncea diet and their effect on hepatic glycogen content and the key enzymes of carbohydrate metabolism. Mol. Cell. Biochem., v. 241, p. 95-101, 2002a.

GROVER, J. K.; YADAV, S.; VATS, V. Medicinal plants of India with antidiabetic potential. J. Ethnopharmacol., v. 81, p. $81-100,2002$ b. 
GROVER, J. K.; YADAV, S.; VATS, V. Effect of feeding Murraya koeingii and Brassica juncea diet kidney functions and glucose levels in streptozotocin diabetic mice. J. Ethnopharmacol., v. 85, p. 1-5, 2003.

HANDA, S. S.; CHAWLA, A. S. Hypoglycemic plants - a review. Fitoterapia, v. 60, p. 195-224, 1989.

HAYAMIZU, K.; HIRAKAWA, H.; OIKAWA, D.; NAKANISHI, T.; TAKAGI, T.; TACHIBANA, T.; FURUSE, M. Effect of Garcinia cambogia extract on serum leptin and insulin in mice. Fitoterapia, v. 74, p. 267273, 2003.

HILALY, J. E.; LYOUSSI, B. Hypoglycaemic effect of the lyophilised aqueous extract of Ajuga iva in normal and streptozotocin diabetic rats. J. Ethnopharmacol., v. 80, p. 109-113, 2002.

HNATYSZYN, O.; MIÑO, T.; FERRARO, G.; ACEVEDO, C. The hypoglycemic effect of Phyllanthus sellowianus fractions in streptozotocin-induced diabetic mice. Phytomedicine, v. 9, p.556-559, 2002.

HOSSEINZADEH, H.; RAMEZANI, M.; DANAEI, A. R. Antihyperglycaemic effect and acute toxicity of Securigera securida L. seed extracts in mice. Phytother. Res., v. 16, p. 745-747, 2002.

HOU, C. C.; LIN, S. J.; CHENG, J. T.; HSU, F. L. Antidiabetic dimeric guianolides and a lignan glycoside from Lactuca indica. J. Nat. Prod., v. 66, p. 625-629, 2003.

HUATYSZYN, O.; MIÑO, J.; GORZALCZANY, S.; OPEZZO, J.; FERRARO, G.; COUSSIO, J.; ACEVEDO, C. Diuretic activity of na aqueous extract of Phyllanthus sellowianus. Phytomedicine, v. 6, p. 177$179,1999$.

HUO, Y.; WINTERS, W. D.; YAO, DA-LIN. Prevention of diet-induced type 2 diabetes in the C57BL/6J mouse model by an antidiabetic herbal formulae. Phytother. Res., v. 17, p. 48-55, 2003.

IVORRA, M. D.; PAYÁ, M.; VILLAR, A. A review of natural products and plants as potential antidiabetic drugs. J. Ethnopharmacol., v. 27, p. 243-275, 1989.
JAOWHARI, J. T.; LAZREK, H. B.; SEDDIK, A.; JAN, M. Hypoglycemic response to Zygophyllum gaetulum extracts in patients with non-insulin-dependent diabetes mellitus. J. Ethnopharmacol., v. 64, p. 211-216, 1999.

JAYAKAR, B.; SURESH, B. Antihyperglycemic and hypoglycemic effect of Aporosa lindleyana in normal and alloxan induced diabetic rats. J. Ethnopharmacol., v. 84, p. 247-249, 2003.

JEPRESEN, P. B.; GREGENSEN, S.; ALSTRUP, K. K.; HERMANSEN, K. Stevioside induces antihyperglycaemic, insulinotropic and glucagonostatic effects in vivo: studies in the diabetic Goto-kakizaki (GK) rats. Phytomedicine, v. 9, p. 9-14, 2002.

JOHNS, T.; CHAPMAN, L. Phytochemicals ingested in traditional diets and medicine as modulators of energy metabolism. In: ARNASON, J. T.; MATA, R.; ROMEO, J. T., (Eds.). Recent Advances in Phytochemistry. New York: Plenum Press, 1995, v. 29, p.161-188.

JOUAD, H.; EDDOUKS, M.; LACAILLE-DUBOIS, M. A.; LYOUSSI, B. Hypoglyacaemic effect of Spergularia purpurea in normal and streptozotocininduced diabetic rats. J. Ethnopharmacol., v. 71, p. 169177,2000 .

JOUAD, H.; MAGHRANI, M.; EDDOUKS, M. Hypoglycaemic effect of Rubus fructicosis L. and Globularia alypum L. in normal and streptozotocin induced diabetic rats. J. Ethnopharmacol., v. 81, p. 351$356,2002$.

KAMEI, R.; KADOKURA, M.; KITAGAWA, Y.; HAZEKI, O.; OIKAWA, S. 2'-Benzyloxychalcone derivatives stimulate glucose uptake in 3T3-L1 adipocytes. Life Sci., v. 73, p. 2091-2099, 2003.

KAMESWARA RAO, K. B.; GIRI, R.; KESAVULU, M. M.; APPARAO C. Effect of oral administration of bark extract of Pterocarpus santalinus L. on blood glucose level in experimental animals. J. Ethnopharmacol., v. 74, p. $69-74,2001$ a.

KAMESWARA RAO, K. B.; KESAVULU, M. M.; APPARAO C. Antihyperglycemic activity of Mormodica cymbalaria in alloxan diabetic rats. $J$. Ethnopharmacol., v. 78, p. 67-71, 2001 b. 
KAMESWARA RAO, K. B.; KESAVULU, M. M.; APPARAO C. Evaluation of antidiabetic effect of Mormodica cymbalaria fruit in alloxan diabetic rats. Fitoterapia, v. 74, p. 7-13, 2003.

KANTH, V. R.; DIWAN, P. V. Analgesic, antiinflammatory and hypoglycaemic activities of Sida cordifolia. Phytother. Res., v. 13, p, 75-77, 1999.

KANEGUSUKU, M.; BENASSI, J. C.; PEDROSA, R. C.; YUNES, R. A.; FILHO, V. C.; MAIA, A. A.; De SOUZA, M. M.; DELLE MONACHE, F.; NIERO, R. Cytotoxic, hypoglycemic activity and phytochemical analysis of Rubus imperialis (Rosaceae). Z. Naturforsch, C, v. 57, p, 272-276, 2002.

KAR, A.; CHAUDHARY, B. K.; BANDYOPADHYAY, N. G. Prelimonary studies on the inorganic constituents of some indigenous hypoglycaemic herbs on oral glucose tolerance test. J. Ethnopharmacol., v. 64, p. 179-184, 1999.

KAR, A.; CHAUDHARY, B. K.; BANDYOPADHYAY, N. G. Comparative evaluation of hypoglycaemic activity of some indian medicinal plants in alloxan diabetic rats. $J$. Ethnopharmacol., v. 84, p. 105-108, 2003.

KAVALALI, G.; TUNCEL, H.; GÖKSEL, S.; HATEMI, H. H. Hypoglycemic activity of Urtica pilulifera in streptozotocin diabetic rats. J. Ethnopharmacol., v. 84, p. 241-245, 2003.

KIM, B. Y.; AHN, J. B.; LEE, H. W.; KANG, S. K.; LEE, J. H.; SHIN, J. S.; AHN, S. K.; HONG, C. I.; YOON, S. S. Synthesis and biological activity of novel substituted pyridines and purines containing 2,4-thiazolidinedione. Eur. J. Med. Chem., v. 39, p. 433-447, 2004.

KORKMAZ, H.; GÜRDAL, A. Effect of Artemisia santonicum L. on blood glucose in normal and alloxaninduced diabetic rabbits. Phytother. Res., v. 16, p. 675$676,2002$.

KORYTAR, P.; SIVONOVA, M.; MARUNIAKOVA, A.; ULICNA, O.; KVASNICKA, P.; LIPTAKOVA, A.; BOZEK, P.; CARSKY, J.; DURACKOVA, Z. Influence of 2,5-dihydroxybenzylidene aminoguanidine on lipid oxidatrive damage and on antioxidant levels in model diabetes mellitus. Pharmazie, v. 58, p. 733-737, 2003.
KOSHY, A. S.; VIJAYALAKSHMI, R. Impact of certain flavonoids on lipid profiles. Potential action of Garcinia cambogia flavonoids. Phytother. Res., v. 15, p. 395-400, 2001.

KRENISKY, J. M.; LUO, J.; REED, M. J.; CARNEY, J. R. Isolation and antihyperglycemic activity of bakuchiol from Otholobium pubescens (Fabaceae), a Peruvian medicinal plant used fro the treatment of diabetes. Biol. Pharm. Bull., v. 22, p. 1137-1140, 1999.

KUBO, H.; KOBAYASHI, J.; HIGASHIYAMA, K.; KAMEI, J.; FUJII, Y.; OHMIYA, S. The hypoglycemic effect of (7R, 9aS)-7-phenyl-octahydroquinolizin-2-one in mice. Biol. Pharm. Bull., v. 23, p. 1114-1117, 2000.

LADEJI, O.; OMEKARAH, I.; SOLOMON, M. Hypoglicemic properties of aqueous bark extract of Ceiba pentandra in streptozotocin induced diabetic rats. J. Ethnopharmacol., v. 84, p. 139-142, 2003.

LAMBA, S. S.; BUCH, K.Y.; LEWIS, H.; LAMBA, H. J. Phytochemicals as potential hypoglycemic agents. Studies in Natural Products Chemistry, v. 21, p. $457-$ 495, 2000 .

LAURenZ, J. C.; COllier, C. C.; KUTI, J. O. Hypoglycaemic effect of Opuntia lindheimeri Englem in a diabetic pig model. Phytother. Res., v. 17, p. 26-29, 2003.

LEIRO, J. M.; ALVAREZ, E.; ARRANZ, J. A.; SISO, I. G.; ORALLO, F. In vitro effects of mangiferin on superoxide concentrations and expression of the inducible nitric oxide synthase, tumour necrosis factor-alpha and transforming growth factor-beta genes. Biochem. Pharmacol., v. 65, p. 1361-1371, 2003.

LI, W. L.; ZHENG, H. C.; BUKURU, J.; De KIMPE, N. Natural medicines used in the traditional chinese medical system for therapy of diabetes mellitus. $J$. Ethnopharmacol., v. 92, p. 1-21, 2004.

LI, S. Q.; COVINO, N. D.; STEIN, E. G.; TILL, J. H.; HUBBARD, S. R. Structural and biochemical evidence for an autoinhibitory role for tyrosine 984 in the juxtamembrane region of the insulin receptor. J. Biol. Chem., v. 278, p. 26007-26014, 2003. 
LIENHARD, G. E.; SHOT, J. W.; JAMES, D. E.; MUECKLER, M. M. How cells absorb glucose. Sci. Amer., v. 266, p. 86-91, 1992.

LINO, C. D.; DIOGENES, J. P. L.; PEREIRA, B. A.; FARIA, R. A. P. G.; NETO, M. A.; ALVES, R. S.; De QUEIROZ, M. G. R.; De SOUSA, F. C. F.; VIANA, G. S. B. Antidiabetic activity of Bauhinia forticata extracts in alloxan-diabetic rats. Biol. Pharm. Bull., v. 27, p. 125$127,2004$.

LIU, I. M.; CHI, T. C.; HSU, F. L.; CHEN, C. F.; CHENG, $\mathrm{J}$. T. Isoferulic acid as active principle from the rhizoma of Cimicifuga dahurica to lower plasma glucose in diabetic rats. Planta Medica, v. 65, p. 712-714, 1999.

MALALAWIDHANE, T. S.; WICKRAMASINGHE, S. M.; JANSG, E. R. Oral hypoglycaemic activity of Ipomoea aquatica. J. Ethnopharmacol., v. 72, p. $293-$ 298, 2000.

MALALAWIDHANE, T. S.; WICKRAMASINGHE, S. M.; JANSG, E. R. An aqueous extract of the green leafy vegetable Ipomoea aquatica is as effective as the oral hypoglycaemic drug tolbutamide in reducing the blood sugar levels of Wistar rats. Phytother. Res., v. 15, p. 635 $-637,2001$

MALLAVADHANI, U. V.; SAHU, G. Pterostilbene: a highly reliable quality-control marker for the Ayurvedic antidiabetic plant 'Bijasar'. Chromatographia, v. 58, p. 307-312, 2003.

MARLES, R. J.; FARNSWORTH, N. R. Antidiabetic plants and their active constituents. Review. Phytomedicine, v. 2,p. 137-189, 1995.

MAROO, J.; VASU, T. V.; AALINKEEL, R.; GUPTA, S. Glucose lowering effect of aqueous extract of Enicostemma littorale Blume in diabetes: a possible mechanism of action. J. Ethnopharmacol., v. 81, p. 317 $-320,2002$.

MAROO, J.; VASU, T. V.; GUPTA, S. Dose dependent hypoglycemic effect of aqueous extract of Enicostemma littorale Blume in alloxan induced diabetic rats. Phytomedicine, v. 10, p. 196 - 199, 2003.
MARUKAMI, T.; KISHI, A.; YOSHIWAWA, M. Medicinal flowers IV. Marigold: structures of new ionone and sesquiterpene glycosides from egyptian Calendula officinalis. Chem. Pharm. Bull., v. 49, p. 974-978, 2001.

McCUNE, L. M.; JOHNS, T. Antioxidant activity in medicinal plants associated with the symptons of diabetes mellitus used by indigenous peoples of the North American Boreal Forest. J. Ethnopharmacol., v. 82, p. 197-205, 2002.

MICHELLYS, P. Y.; ARDECKY, R. J.; CHEN, J. H.; CROMBLE, D. L.; ETGEN, G. J.; FAUL, M. M.; FAULKNER, A. L.; GRESE, T. A.; HEYMAN, R. A.; KARANEWSKY, D. S.; KLAUSING, K.; LEILOWITZ, M. D.; LIU, S.; MAIS, D. A.; MAPES, C. M.; MARSCHLE, K. B.; REIFEL-MILLER, A.; OGILVIE, K. M.; RUNGTA, D.; THOMPSON, A. W.; TYHONAS, J. S.; BOEHM, M. F. Novel (2E,4E,6Z)-7(2-alkoxy-3,5-dialkylbenzene)-3-methylocta-2,4,6-trienoic acid retinoid $\mathrm{X}$ receptor modulators are active in models of type 2 diabetes. J. Med. Chem., v. 46, p. 2683-2696, 2003.

MIURA, T.; ICHIKI, H.; IWAMOTO, N.; KATO, M.; KUBOS, M.; SASAKI, H.; OKADA, M.; ISHIDA, T.; SEINO, Y.; TANIGAWA, K. Antidiabetic activity of the Rhizoma of Anemarrhena asphodeloides and active components, mangiferin and its glucoside. Biol. Pharm. Bull., v. 24, p. 1009-1111, 2001a.

MIURA, T.; ICHIKI, H.; HASHIMOTO, I.; IWAMOTO, N.; KATO, M.; KUBO, M.; ISHIHARA, E.; KOMATSU, Y.; OKADA, M.; ISHIDA, T.; TANIGAWA, K. Antidiabetic activity of xanthone compound mangiferin. Phytomedicine, v. 8, p. 85-87, $2001 b$.

MIURA, T.; ITOH, Y.; IWAMOTO, N.; KATO, M.; ISHIDA, T. Suppressive activity of the fruit of Momordica charantia with exercise on blood glucose in type 2 diabetic mice. Biol. Pharm. Bull., v. 27, p. 248-250, 2004.

MOSHI, M. J.; LUTALE, J. J. K.; RIMOY, G. H.; ABBAS, Z. G.; JOSIAH, R. M.; SWAI, A. B. M. The effect of Phyllanthus amarus aqueous extract on blood glucose in non-insulin dependent diabetic patients. Phytother. Res., v. 15, p. $577-580,2001$. 
MURALI, B.; UPADHYAYA, U. M.; GOYAL, R. K. Effect of chronic treatment with Enicostemma littorale in non-insulin dependent diabetic (NIDDM) rat. $J$. Ethnopharmacol., v. 81, p. 199-204, 2002.

MUTALIK, S.; UDUPA, N. Glibenclamide transdermal patches: physicochemical, pharmacodynamic and pharmacokinetic evaluations. J. Pharm. Sci., v. 93, p.1577-1594, 2004

NEEF, H.; DECLERCQ, P.; LAEKEMAN, G. Hypoglycaemic activity of selected European plants. Phytother. Res., v. 9, p. 45-48, 1995.

NOGUEIRA, L. Mais conforto e eficiência. Pesquisa FAPESP-Ciência e Tecnologia no Brasil, v. 89, p. 7879, 2003.

NOVAES, A. P.; ROSSI, C.; POFFO, C.; PRETTI JÚNIOR, E.; OLIVEIRA, A. E.; SCHLEMPER, V.; NIERO, R.; CECHINEL-FILHO, V.; BÜRGER, C. Preliminary evaluation of the hypoglycemic effect of some Brazilian medicinal plants. Therapie, v. 56, p. 427430, 2001.

NYARKO, A. K.; ASARE-ANANE, H.; OFOSUHENE, M.; ADDY, M. E. Extract of Ocimum canun lowers blood glucose and facilitates insulin release by isolated pancreatic beta-islet cells. Phytomedicine, v. 9, p. 346$350,2002$.

OJEWOLE, J. A. O. Hypoglycaemic effect of Clausena anisata (willd) Hook methanolic root extract in rats. $J$. Ethnopharmacol., v. 81, p. 231-237, 2002.

OJEWOLE, J. A. O. Hypoglycemic effect of Scleocarya birrea (A. Rich Hochst) [Anacardiaceae] stem-bark aqueous extract in rats. Phytomedicine, v. 10, p. 675-681, 2003.

OKYAR, A.; CAN, A.; AKEV, N.; BAKTIR, G.; SUTLÜPINAR, N. Effect of Aloe vera leaves on blood glucose level in type I and type II diabetic rat models. Phytother. Res., v. 15, p. 157-161, 2001.

OLIVEIRA, F.; SAITO, M. L. Alguns vegetais brasileiros empregados no tratamento da diabetes. Rev. Bras. Farm., v. 2-4, p. 137-189, 1995.
PARI, L.; VENKATESWARAN, S. Hypoglycaemic activity of Scoparia dulcis L. extract in alloxan induced hyperglycaemic rats. Phytother. Res., v. 16, p. 662-664 2002.

PARI, L.; LATHA, M. Antidiabetic activity of Cassia auriculata flowers: effect on lipid peroxidation in streptozotocin diabetes rats. Pharm. Biol., v. 40, p. 512$517,2002$.

PARI, L.; SATHEESH, M. A. Antidiabetic activity of Boerhaavia diffusa L.: effect on hepatic key enzymes in experimental diabetes. J. Ethnopharmacol., v. 91, p. 109-113, 2004.

PEPATO, M. T.; FOLGADO, V. B.; KETTELHUT, I. C.; BRUNETTI, I. L. Lack of antidiabetic effect of a Eugenia jambolana leaf decoction on rat streptozotocin diabetes. Braz. J. Med. Biol. Res., v. 34, p. 389-395, 2001.

PEPATO, M. T.; KELLER, E. H.; BAVIERA, A. M.; KETTELHUT, I. C.;VENDRAMINI, R. C.; BRUNETTI, I. L. Antidiabetic activity of Bauhinia forticata decoction in streptozotocin-diabetic rats. $J$. Ethnopharmacol., v. 81, p. 191-197, 2002.

PEREIRA, N. A. Plants as hypoglycemic agents. Ciência e Cultura, v. 49, p. 354-358, 1997.

PEREZ GUTIÉRREZ, R. M.; ZAVALA, S. M. A.; PEREZ, G. S.; PEREZ, G. C. Antidiabetic effect of compounds isolated from plants. Phytomedicine, v. 5, p. 55-75, 1998.

PEREZ GUTIÉRREZ, R. M.; CERVANTES, C. H.; ZAVALA, S. M. A.; SANCHEZ, A. J.; PEREZ, G. S.; PEREZ, G. C. Isolation and hypoglycemic activity of 5, 7, 3'-tryhydroxy-3,6,4'-trimetoxiflavona from brickellia veronicaefolia. Phytomedicine, v. 7, p. 25-29, 2000a.

PEREZ GUTIÉRREZ, R. M.; PEREZ, C.; ZAVALA, M.A.; PEREZ, S.; HERNANDEZ, H.; LAGUNES, F. Hypoglycemic effects of lactucin-8-O-methylacrylate of Parmentiera edulis fruit. J. Ethnopharmacol., v. 71, p. 391-394, 2000b.

PEREZ GUTIÉRREZ, R. M.; RAMIREZ, E. L. M.; VARGAS, R. S. Effect of Cirsium pascuarense on blood glucose levels of normoglycaemic and alloxan-diabetic mice. Phytother. Res., v. 15, p. 552-554, 2001. 
PEREZ GUTIÉRREZ, R. M. Compuestos aislados de plantas com actividad antiinflamatoria, antiviral e hipoglicemiante. México: Instituto Politécnico Nacional, 2002a. p. 139-185.

PEREZ GUTIÉRREZ, R. M.; VARGAS, R. S. Triterpenos from Agarista mexicana as potential antidiabetic agents. Phytother. Res., v. 16, p. 55-58, 2002 b.

PEUNGVICHA, P.; TEMSIRIRIRKKUL, R.; PRASAIN, J.K.; TEZUKA, Y.; KADOTA, S.; THIRAWARAPAN, S. S.; WATANABE, H. 4-Hydroxybenzoic acid: a hypoglicemic constituent of aqueous extract of Pandanus odorus root. J. Ethnopharmacol., v. 62, p. 79-84, 1998.

PRINCE, P. S. M.; KAMALAKKANNAN, N.; MENON, V. P. Syzigium cumini seed extracts reduce tissue damage in diabetic rat brain. J. Ethnopharmacol., v. 84, p. 205-209, 2003.

PRINCE, P. S. M.; MENON, V. P. Antioxidant action of Tinospora cordifolia root extract in alloxan diabetic rats. Phytother. Res., v. 15, p. 213-218, 2001.

PURI, D. The insulinotropic activity of a Nepalese medicinal plant Biophytum sensitivum; preliminary esperimental study. J. Ethnopharmacol., v. 78, p. 89-93, 2001.

PUSHPARAJ, P. N.; HUATTAN, B. K.; TAN, C. H. The mechanism of hypoglycemic action of the semi-purified fractions of Averrhoa bilimbi in streptozotocin-diabetic rats. Life Sci., v. 70, p. 535-547, 2001.

RAHMAN, A-U.; ZAMAN, K. Medicinal plants with hypoglycemic activity. J. Ethnopharmacol., v. 26, p. 1$55,1989$.

RAO, A. V.; GURFINKEL, D. M. The bioactivity of saponins: triterpenoid and steroidal glycosides. Drug Metabol. Drug Interact., v. 17, p. 211-235, 2000.

RAO, K. B.; RAO. A. Ch. Hypoglycemic and antihyperglycemic activity of Syzygium alternifolium (WT) Walp. Seed extracts in normal and diabetic rats. Phytomedicine, v. 8, p. 88-93, 2001.

RAO, B. R.; MURUGESAN, T.; SINHA, S.; SAHA, B. P.; PAL, M.; MANDAL, S. C. Glucose lowering efficacy of Ficus racemosa bark extract in normal and alloxan diabetic rats. Phytother. Res., v. 16, p. 590-592, 2002.
RAO, K. B.; SUDANSHAN, P. R.; RAJASEKHAR, M. D.; NAGARAJU, N.; RAO. A. Ch. Antidiabetic activity of Terminalia pallida fruit in alloxan induced diabetic rats. J. Ethnopharmacol., v. 85, p. 169 -172, 2003.

RATHI, S. S.; GROVER, J. K.; VATS, V. The effect of Momordica charantia and Mucuna pruriens in experimental diabetes and their effect on key metabolic enzymes involved in carbohydrate metabolism. Phytother. Res., v. 16, p. 236-243, 2002a.

RATHI, S. S.; GROVER, J. K.; VATS, V.; BISWAS, N. R. Prevention of experimental diabetic cataract by Indian Ayurvedic plant extracts. Phytother. Res., v. 16, p. 774$777,2002 b$.

REVILLA, M. C.; ANDRADE-CETTO, A.; ISLAS, S.; WIEDENFELD, H. Hypoglycemic effect of Equisetum myriochaetum aerial portion type 2 diabetic patients. $J$. Ethnopharmacol., v. 81, p. 117-120, 2002.

ROBBINS, S. L.; COTRAN, R. S.; KUMAR, V.; TARANTO, G. Patologia estrutural e funcional. 4. ed. Rio de Janeiro: Guanabara Kogan, 1991.p. 817-826.

SABU, M. C.; SMITHA, K.; KUTTAN, R. Antidiabetic activity of green tea polyphenols and their role in reducing oxidative stress in experimental diabetes. $J$. Ethnopharmacol., v. 83, p. 109-116, 2002a.

SABU, M. C.; KUTTAN, R. Antidiabetic activity of medicinal plants and its relationship with their antioxidant property. J. Ethnopharmacol., v. 81, p. 155-160, 2002b.

SABU, M. C.; SUBBURAJU, T. Effect of Cassia auriculata Linn on serum glucose level, glucose utilization by isolated rat hemidiaphragm. J. Ethnopharmacol., v. 80, p. 203-206, 2002c.

SACHDEWA, A.; KHEMANI, L. D. Effect of Hibiscus rosa sinensis Linn. Ethanol flower extract on blood glucose and lipid profile in streptozotocin induced diabetes in rats. J. Ethnopharmacol., v. 89, p. 61-66, 2003.

SAID, O.; KHALIL, K.; FULDER, S.; AZAIZEH, H. Ethnopharmacological survey of medicinal herbs in Israel, the Golan Heights and the West Bank Region. $J$. Ethnopharmacol., v. 83, p. 251-265, 2002. 
SAXENA, A.; VIKRAM, N. K. Role of selected Indian plants in management of type 2 diabetes: a review. $J$. Altern. Complem. Med., v. 10, p. 369-378, 2004.

SEETHARAM, Y. N.; CHALAGERI, G.; RAMACHANDRA, S.; BHEEMACHAR, S. Hypoglycemic activity of Abutilon indicum leaf extracts in rats. Fitoterapia, v. 73, p. 156-159, 2002.

SENANAYAKE, G. V. K.; MARUYAMA, M.; SHIBUYA, K.; SAKONO, M.; FUKUDA, N.; MORISHITA, T.; YUKIZAKI, C.; KAWANO, M.; OHTA, H. The effects of bitter melon (Momordica Charantia) on serum and liver triglyceride levels in rats. J. Ethnopharmacol., v. 91, p. 257-262, 2004.

SHIM, Y-J.; DOO, H-K.; AHN, S-Y.; KIM, Y-S.; SCONG, J-K.; PARK, I-S, MIN, B-H. Inhibitory effect of aqueous extract from the gall of Rhus chinensis on alphaglucosidase activity and post prandial blood glucose. $J$. Ethnopharmacol., v. 85, p. 283-287, 2003.

SHIRWAIKAR, A.; RAJENDRAN, K.; KUMAR, C. D.; BODIA, R. Antidiabetic activity of aqueous leaf extract of Annona squamosa in streptpzotocin-nicotinamide type 2 diabetic rats. J. Ethnopharmacol., v. 91, p. 171-175, 2004.

SHANG, J.; LEHRMAN, M. A. Metformin-stimulated mannose transport in dermal fibroblasts. J. Biol. Chem., v. 279, p. 9703-9712, 2004.

SHOELSON, S. E. Insulin and other antidiabetic agents. KirkOthmer Encyclopedia of Chemical Technology, 3th. Edn, John Wiley, New York, v. 14, p. 662-676, 1995.

SILVA, R. M.; SANTOS, F. A.; RAO, V. S.; MACIEL, M. A.; PINTO, A. C. Blood glucose and triglyceride-lowering effect of trans-dehydrocrotonin, a diterpene from Croton cajucara Benth. in rats. Diabetes Obes. Metab., v. 3, p. 452-456, 2001.

SILVA, F. R. M. B.; SZPOGANICZ, B.; PIZZOLATTI, M. G.; VIEIRA WILLRICH, M. A.; de SOUSA, E. Acute effect of Bauhinia forticata on serum glucose levels in normal and alloxan-induced diabetic rats. $J$. Ethnopharmacol., v. 83, p. 33-37, 2002.
SILVA, C.; RIBEIRO, A.; FERREIRA, D.; VEIGA, F. Administração oral de peptídeos e proteínas III. Aplicação à insulina. Rev. Bras. Cienc. Farm., v. 39, p. 21-40, 2003.

SOMOVA, L. O.; NADAR, A.; RAMMANAN, P. SHODE, F. O. Cardiovascular, antihyperlipidemic and antioxidant effects of oleanolic and ursolic acids in experimental hypertension. Phytomedicine, v. 10, p. 115121,2003.

SYIEM, D.; SYNGAI, G.; KHUP, P. Z.; KHONGWIR, B. S.; KHARBULI, B.; KAYANG, H. H. Hypoglycemic effects of Potentilla fulgens L. in normal and alloxaninduced diabetic mice. J. Ethnopharmacol., v. 83, p. 55$61,2002$.

TEIXEIRA, C. C.; RAVA, C. A.; da SILVA, P. M.; MELCHIOR, R.; ARGENTA, R.; ANSELMI, F.; ALMEIDA CHIAREL, C. R.; FUCHS, F. D. Absence of antihyperglycemic effect of jambolan in experimental and clinical models. J. Ethnopharmacol., v. 71, p. 343347,2000 .

TOLAN, I.; RAGOUBIRSINGH, D.; MORRISON, E. Y. S. I.A. The Effect of capsaicin on blood glucose, plasma insulin levels and insulin in binding in Dog models. Phytother. Res., v. 15, p. 391-394, 2001.

UGOCHUKWU, N. H.; BABADY, N. E. Antioxidant effects of Gongronema latifolium in hepatocytes of rat models of non-insulin dependent diabetes mellitus. Fitoterapia, v. 73, p. 612-618, 2002.

VENANCIO, T. M.; OLIVEIRA, A. E. A.; SILVA, L. B.; MACHADO, O. L. T.; FERNANDES, K. V. S.; XAVIER, J. A protein with amino acid sequence homology to bovine insulin is present in the legume Vigna unguiculata (cowpea). Braz. J. Med. Biol. Res., v. 36, p. 1167-1173, 2003.

VENKATESH, S.; REDDY DAYANAND, G.; REDDY MADHAVA, B.; RAMESH, M.; RAO APPA, A. V. N. Antihyperglycemic activity of Caralluma attenuata. Fitoterapia, v. 74, p. 274-279, 2003.

VENKATESWARAN, S.; PARI, L. Effect of Coccinia indica leaves on antioxidant status in streptozotocininduced diabetic rats. J. Ethnopharmacol., v. 84, p. 163$168,2003$. 
VETRICHELVAN, T.; JEGADEESAN, M. Antidiabetic activity of alcoholic extract of Aerva lanata (L) Juss ex. Schultes in rats. J. Ethnopharmocol., v. 80, p. 103-107, 2002.

VIKRANT, V.; GROVER, J. K.; TANDON, N.; RATHI, S. S.; GUPTA, N. Treatment with extracts of Momordica charantia and Eugenia jambolana prevents hyperglycemia and hyperinsulinemia in fructose fed rats. J. Ethnopharmacol, v. 76, p. 139-143, 2001.

VIKRANT, V.; GROVER, J. K.; RATHI, S. S. Evaluation of anti-hyperglycemic and hypoglycemic effect of trigonella Foenum-graecum Linn, Ocimum sanctum Linn and Pterocarpus marsupium Linn in normal and alloxanized diabetic rats. J. Ethnopharmacol., v. 79, p. 95-100, 2002.

VILHAUER, E. B.; BRINKMAN, J. A.; NADERI, G. B.; BURKEY, B. F.; DUNNING, B. E.; PRASAD, K.; MANGOLD, B. L.; RUSSELL, M. E.; HUGHES, T. E. 1-[[3-Hydroxy-1-adamantyl)amino]acetyl]-2-cyano-(S)pyrrolidine: a potent, selective and orally bioavailable dipeptidyl peptidase IV inibidor with antihyperglycemic properties. J. Med. Chem., v. 46, p. 2774-2789, 2003.

VIRDI, J.; SIVAKAMI, S.; SHAHANI, S.; SUTHAR, A. C.; BANAVALIKAR, M. M.; BIYANI, M. K. Antihyperglycemic effects of three extracts from Momordica charantia. J. Ethnopharmacol., v. 88, p. 107-111,2003.

VOLPATO, G. T.; DAMASCENO, D. C.; CALDERON, I. M. P.; RUDGE, M. V. C. Revisão de plantas brasileiras com comprovado efeito hipoglicemiante no controle do Diabetes mellitus. Rev. Bras. Pl. Med., v. 4, p.35-45, 2002.
WANG, H. X.; NG, T. B. Natural products with hypoglycemic, hypotensive, hypocholesterolemic, antistherosclerotic and antithrombotic activities. Life Sci., v. 65, p. $2663-2677,1999$.

WORLD HEALTH ORGANIZATION. WHO Monographs on Selected Medicinal Plants. Report of a WHO study group. WHO Technical Report Series, WHO, Geneva, v. 2, p. 110, 2002a.

WORLD HEALTH ORGANIZATION. WHO Monographs on Selected Medicinal Plants. Report of a WHO study group. WHO Technical Report Series, WHO, Geneva, v. 2, p. 211, 2002b.

XIE, J. T.; ZHOU, Y-P.; DEY, L.; ATTELE, A. S.; WU, J. A.; GU, M.; POLONSKY, K. S.; YUAN, C-S. Ginseng berry reduces blood glucose and body weight in $\mathrm{db} / \mathrm{db}$ mice. Phytomedicine, v. 9, p. 254-258, 2002.

YADAV, S.; VATS, V.; DHUNNOO, Y.; GROVER, J. K. Hypoglycemic and antihyperglycemic activity of Murraya koenigii leaves in diabetic rats. $J$. Ethnopharmocol., v. 82, p. 111-116, 2002.

YOSHIKAWA, M.; MURAKAMI, T.; KISHI, A.; KAGENRA, T.; MATSUDA, H. Medicinal flowers. Marigold. Hypoglicemic, gastric emptying inihibitory and gastroprotective principles and new oleanano-type, triterpene oligoglicosides, calendasaponins A, B, C, and D, from Egyptian Calendula officinalis. Chem. Pharm. Bull., v. 49, p. 863-870, 2001.

Recebido para publicação em 12 de agosto de 2003 Aceito para publicação em 25 de março de 2005 